Review

\title{
Staying Coherent After Kent: From Optical Communications to Biomedical Optics
}

\author{
David D. SAMPSON \\ Optical+Biomedical Engineering Laboratory, School of Electrical, Electronic \& Computer Engineering and Centre for \\ Microscopy, Characterisation \& Analysis, the University of Western Australia, Crawley, Western Australia, Australia \\ *Corresponding author: David D.SAMPSONＥ-mail: David.Sampson@uwa.edu.au
}

\begin{abstract}
In this paper, an overview of author's research is presented, commencing at the University of Kent under Prof. David A. Jackson. Early research in short optical pulses and fiber-optic delay-line digital correlators led to optical communications research in code-division multiple access networking. This research was based on broadband incoherent light, and this theme continued with research into spectrum-sliced wavelength-division multiplexing. In shifting from photonics research to biomedical optics and biophotonics in the late 1990s, the emphasis on exploiting broadband light continued with research in optical coherence tomography, amongst other topics. In addition to the research outcomes, how these outcomes were attained is described, including mention of the exceptional contributions of many of my colleagues.
\end{abstract}

Keywords: Digital correlators, optical code-division multiple access, wavelength-division multiplexing, biomedical optics, optical coherence tomography

\section{The road to Kent}

It is an exceptional opportunity to review one's own research and for this I am grateful to the Guest Editor David Jackson and the Editor-in-Chief Yunjiang Rao. In order to provide more than a dry rendering of this account and to properly describe the research milieu, I have included more personal detail than is the norm in our literature - I hope the reader will afford me some leeway on this.

When I left the University of Western Australia as a young man, my first employment was in the oil and gas industry, working as a Schlumberger engineer in the Dutch sector of the North Sea and in the Mediterranean Sea off the coast of Sicily. I soon tired of the oil business and after three years returned to Australia, where I turned to research and in 1987 found myself in Canberra working for Scott
Rashleigh in a start-up company, Australian Optical Fiber Research (AOFR). Scott had returned to Australia with a strong reputation in optical fiber sensors [1] from his time at the Naval Research Laboratory in Washington D. C., USA. Scott's and David Jackson's paths had already crossed, during David's sabbatical there in 1979. Although I interacted little with Scott during my 18 months at AOFR, it was a great place to learn fiber optics and optoelectronics. There were some very good people at AOFR, but none better than Robert Griffin, a quietly spoken young man from Wingello, the childhood home of Australia's other cricket legend, the mercurial Bill O'Reilly, in turn, just down the road from the immortal Don Bradman's home town, Bowral, in the New South Wales southern highlands. In my first project at AOFR, I coupled very small pieces of graded-index multimode fiber with a

Received: 13 July 2011 / Revised version: 3 August 2011

(C) The Author(s) 2011. This article is published with open access at Springerlink.com 
mirror on one end to Fabry-Perot semiconductor lasers in order to convert to single-mode their multi-longitudinal mode operation [2]. Single-mode distributed feedback lasers were not yet widely available. The multimode fiber (cut close to a quarter pitch) functions as a lens - today we use the same technology at the Optical+Biomedical Engineering Laboratory (OBEL) to make microscope-in-a-needle devices (more on this later). The project was sponsored by Australia's Overseas Telecommunications Corporation (later to be merged with Telstra, Australia's national carrier) in its quest to avoid intramodal dispersion in point-to-point links. Soon, I was adapting these same sources to methane spectroscopy in the $1.3-\mu \mathrm{m}$ wavelength band. I generated some very nice high-resolution spectra of lines in the $v_{2}+2 v_{3}$ overtone band at this wavelength (Fig. 1) and produced a very sensitive sensor using $2 f$ spectroscopy [3], none of which was ever published - we were a company after all, and not a university. The topic of gas absorption line shapes remains important to this day [4].

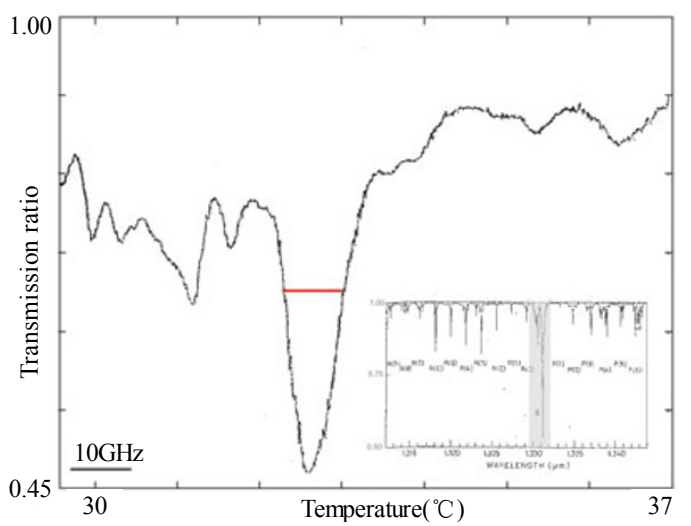

Fig. 1 High-resolution atmospherically broadened methane absorption spectrum at $1331 \mathrm{~nm}$ (inset: $1.3 \mu \mathrm{m}$-band absorption spectrum for reference showing high-resolution portion shaded).

I soon determined that I needed a $\mathrm{PhD}$ and began to look around. Ruling out the US because of an aversion to the obligatory course work, I identified two UK groups in optical fiber technology whose work appeared prominently in Optics Letters and Electronics Letters, the two leading journals of the time - they were David Payne's group at Southampton and David Jackson's at Kent. Having earned a salary for some time and being recently married, I was determined that I could not undertake a PhD on student's wages - an entirely unreasonable position I am sure you will agree. Then something unexpected happened. I wanted to attend the 1988 Bicentennial Congress of the Australian Institute of Physics in Sydney, but AOFR was not keen for me to go. So I took leave and paid my own way. There I met Cyril Edwards who had been my lecturer in Solid State Physics at the University of Western Australia. He told me he was going on sabbatical to David Jackson's lab and would let me know how he found it. Cyril soon wrote that he found it a great place, and at the same time was able to reassure David in taking a punt on an unknown Antipodean. So I went to Kent to take up the position of research fellow working on the digital correlator, funded by the Paul Instrument Fund.

\section{Digital correlators and communications at Kent}

I will never forget the day I arrived at Kent. My wife and I were met on the train platform under a dark and cold afternoon sky in April 1989 by David and Valerie Jackson and taken to a beautiful bungalow - "Belmont" on Giles Lane only minutes from the lab and set high above the town looking down on the majestic and timeless Canterbury Cathedral. Sometimes you have to pinch yourself to be sure things are real - it was a wonderful place and we lived there for the next two years.

A digital correlator is a device for performing an auto- or cross-correlation on digital signals, which had its origins in radar signal processing of the 1940s [5]. At the time, digital correlators were being used mainly in light scattering instrumentation digital versions of the Hanbury-Brown and Twiss experiment [6], such as the Malvern correlator [7] and in astronomy [8] for processing signals from antenna arrays. Julian Jones and David Jackson had 
proposed to build a $1-\mathrm{GHz}$ correlator, exceeding the best electronic correlators by a factor of three or more, in a paper published in Optics Letters [9]. At the time, everyone in the group was involved in sensors and so I would be the first to branch out into what would later become the field of "microwave photonics". I began a crash course in self-taught microwave optoelectronics. Our objective was to build accurate delay line networks and correlate optical pulses. I spent a lot of time reading the works of Howard Shaw's Stanford group [10], that included such luminaries as Michel Digonnet, Kenneth Jackson, Byoung Yoon Kim, Behad Moslehi, Steve Newton, Moshe Tur, Robert Wentworth, Robert Younquist, and sometimes involved contributions from Joseph Goodman [11]. I learned how to gain switch laser diodes to generate short tens-of-picosecond pulses [12], to detect them with high-bandwidth transimpedance receivers (pioneered by John Hullet and Tran Muoi [13], from what would later be my own department - Electrical Engineering at the University of Western Australia (UWA). I built my digital correlator and, with the later help of postdoc William Dove, we eventually published two papers describing it [14, 15]. But Science is a serendipitous game. One day Dave came into the lab and announced an important visitor would tour the lab that afternoon and asked if I could provide a demonstration. I had built a pair of cascaded fiber Mach-Zehnders interferometers in order to generate pulse trains - one pulse in - four pulses out. I had been reading all about incoherent delay line signal processing [11] and thought I would connect the output back into the input and, thus, generate a 1,2,3,4,3,2,1 triangular autocorrelation. But what I saw was, in fact, very close to $1,0,1,16,1,0,1$ - the pulses, though heavily chirped, were perfectly overlapped and phase coherent (Fig. 2). It looked like a nearly perfect autocorrelation. Thus, began my foray into pulse coding, spread-spectrum communications and photonic code-division multiple access, which was to form the last third of my thesis and dominate my research for the next five years.
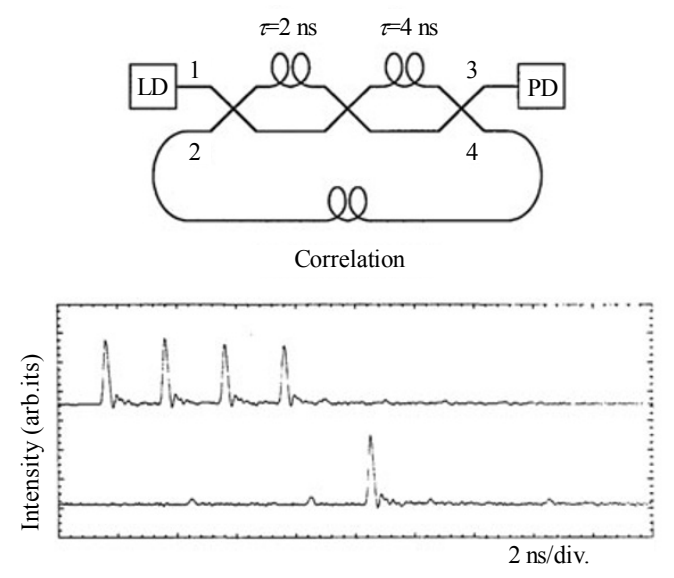

Fig. 2 Pulse network (above) and pulse trains at Port 3 when Ports 2 and 4 are disconnected (upper) and connected (lower), to show coherent correlation. After [14]

The first thing I did was to figure out why the coherent pattern occurred and the next to write my first journal paper. It was duly typed up and posted to Optics Letters. After six weeks or so of silence, I contacted the journal to discover my manuscript had not yet been received. It had been sent sea mail! It was duly published in May 1990 [16] but in the meantime, I discovered a very similar work published in Electronics Letters in October 1989, while my manuscript was at sea, by Marhic and Chang [17]. Parallel tracking Marhic, in particular, would continue for the next few years [18].

Whilst we were caught up in short pulses and ladder networks as means to encode and transmit information, it turned out that others had already investigated single delay pairs under continuous wave operation - so called coherence multiplexing, for information transmission $[19,20]$ and sensing $[21,22]$. The first were Delisle and Cielo publishing in French in 1975 [19], and they were followed by Al Chalabi, Culshaw and Davies [21] in 1983, Brooks et al. [22] in 1985, and then Goedgebauer in 1987 [20, 23].

The next thing David and I did was to write a grant - which I found very exciting. I was the lead chief investigator (CI) and about one year into my 
$\mathrm{PhD}$ we were awarded the grant from the then Science and Engineering Research Council - "All optical processing systems for communications and ranging using pulsed coherent correlation" for $£ 86,297$. Shortly thereafter a tenured lectureship came up in the Physics laboratory and I applied. To my surprise, I was offered the position and so in October 1990, 18 months into my PhD, I found myself a lecturer. My teaching load was very reasonably and generously kept light by the head, John Strange, and for my first course on optoelectronics, I inherited a comprehensive set of beautifully hand-written notes elegantly expounding on the subject produced by Julian Jones, whose office I now occupied. Thus, I felt I knew Julian years before I met him at the International Conference of Optical Fiber Sensors (OFS) in Florence in 1993.

With the grant, we were in a position to recruit a postdoctoral fellow. I turned to my AOFR colleague Rob Griffin and let history repeat itself - he too came to do his PhD at Kent and I had my first student. Those were productive and exciting times as Rob and I learned a new field from scratch. At first, we spent our time thinking about coding and correlation functions and how well we could produce single-peaked autocorrelations and low cross-correlations. My idea was to build cascaded Mach-Zehnders ladder networks that produced pulse sequences and to choose delays judiciously so that pulses were maximally spread to maximize the likelihood of incoherence in cross-correlation. Multiplexed communications could be based on coherent autocorrelation and incoherent cross-correlation. This concept would be explored in depth in papers eventually published in 1994 and much later in 1998 [24, 25]. At the same time, we figured out how to delay match and phase-lock a pair of remote two-stage cascaded Mach-Zehnders (ladder) networks and by amplitude modulating broadband pulses from a gain-switched semiconductor laser, we transmitted on-off-keyed data at $69 \mathrm{Mb} / \mathrm{s}-$ a single user [26]. Rob then came up with the great idea of using a master interferometer phase-locked to all other interferometers, thus, using optical differential phase rather than differential delay as the variable - we demonstrated this in the same year, 1992 [27]. This was closely followed by an even better idea. We had been reading Salehi and Weiner's work on code-division multiple access (CDMA) involving spectral domain femtosecond pulse coding [28], borrowing from Andrew Weiner's earlier work with Jonathan Heritage at Bellcore (see for example [29]). The problem with Salehi and Weiner's approach was that it required transmission of broadband (femtosecond) pulses down optical fibers. To maintain the necessary phase coherence, chromatic dispersion compensation was necessary - a very demanding requirement to this day. Rob realized we could achieve essentially the same spectral phase coding scheme within one arm of an interferometer - we would send the spectrally coded signal and its own reference, thereby negating the effects of dispersion on the code. By choosing judicious spectral phase codes, we could use a network of single delays and vary only the codes - borrowing from our earlier ideas around phase coding [27]. We were very excited about this concept, which made much more practical Salehi and Weiner's elegant idea, and so submitted it as a concept with some rudimentary calculations to Optics Letters. After a lengthy review our paper was rejected after final referral to an eminent person in the field who politely wrote that idea was flawed and impossible. One year later we demonstrated it in the lab [30] and subsequently went on to publish a major paper on this form of CDMA in 1995 [31].

Early on Rob and I had wondered about noise a key element of our designs had been two path interferometers with two outputs - balanced detection enabled us to differentially detect the pulse trains, which left correlation peaks untouched but conveniently cancelled side lobes (Fig. 3). We 
proposed [26] and demonstrated [27] this in 1992. What was left when two pulses cancelled each other? We began our journey into optical beat noise, which extended well beyond my time at Kent. Joseph Goodman's wonderful book Statistical Optics [32], first published in 1985, became our bible. Incoherent interference is the killer for coherence multiplexing and even more so for optical CDMA. Square-law detection means that noise scales with the square of the number of users/sensors, and it cannot be eliminated. Healey was the first to analyze this in the communications context in 1987 [33] and then Chu and Dickey published a more comprehensive analysis based on continuous-wave light [34]. The Stanford group had studied the origins of the same noise, optical beat noise, in great detail in relation to multiplexing interferometric sensors [22, 35]. It would later be studied in relation to spectrum-sliced wavelength division multiplexing systems as well (see below). Meanwhile, there was another branch of optical CDMA based on pulses as well, which assumed perfect incoherence throughout, and never took account of this critical noise source so-called incoherent CDMA [36]. This field was driven mainly by researchers from the field of communications but with no optics background, who had never come across such sources of noise [37]. Thus, a great deal of research was published that never had a chance of realization because of this basic oversight. We tried to debunk these schemes in a review we published in 1997 [38], with limited success, such was its momentum.

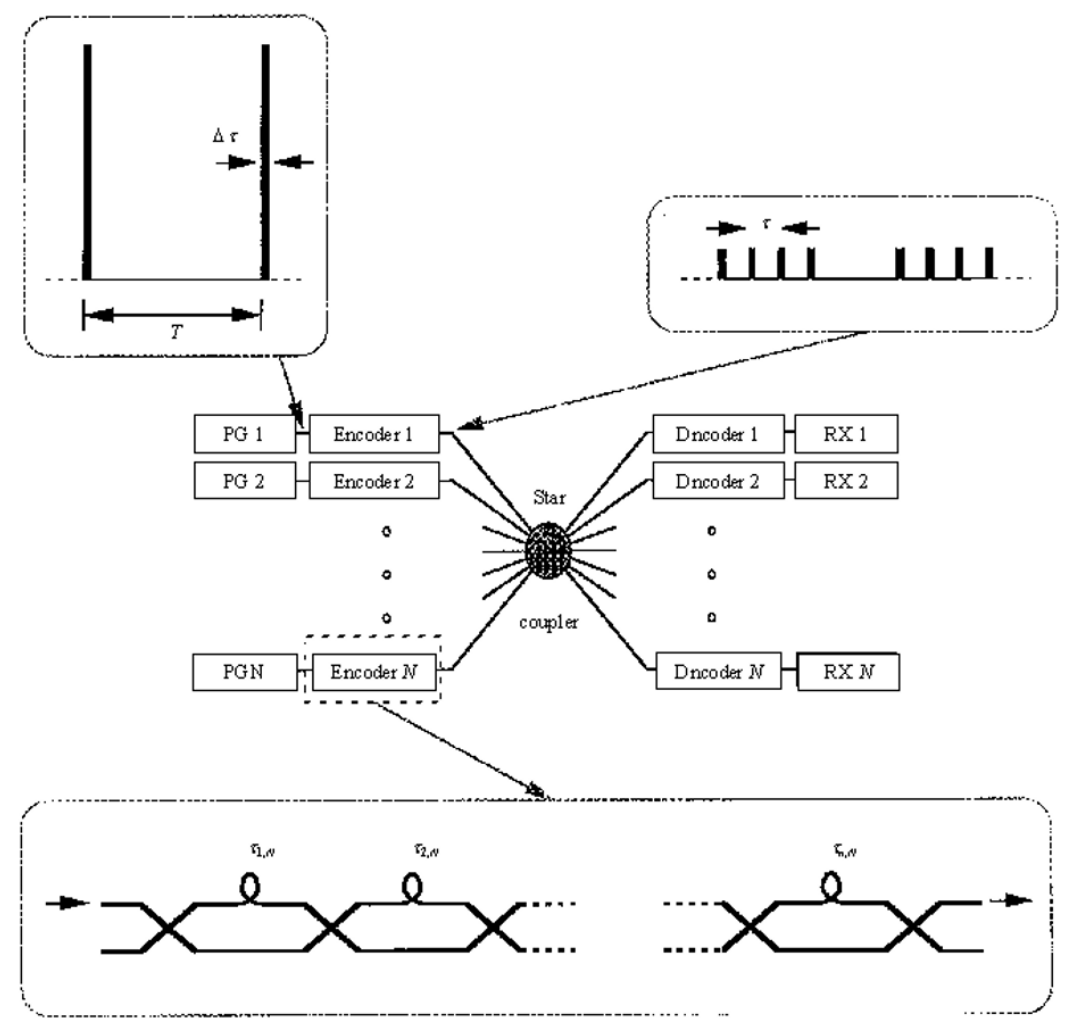

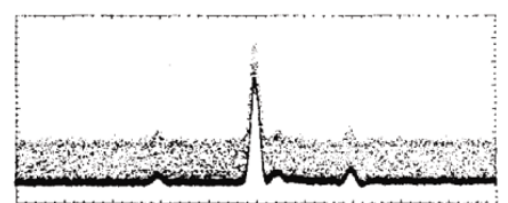

(a)

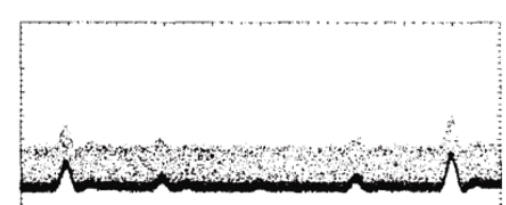

(b)

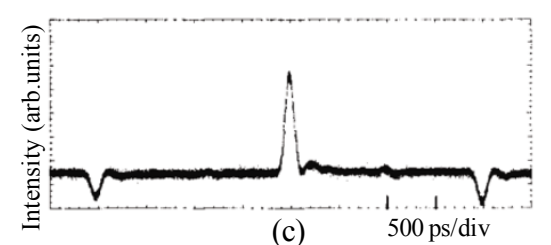

(c)

Fig. 3 Schematic of a "star" access network (above) and coherent matched peak in presence of noise from an unmatched user [curves (a) and (b)) cancelled by balanced detection (curve (c)] [25]. 
My time at Kent was a truly vibrant one. The whole laboratory would duly assemble each morning tea time to gaze out upon the grassy Kent gardens and debate hot topics in fiber sensors, doped fibers, coherent communications, nonlinear optics, which were all fields in photonics in their infancy. In the shadows of the recently departed (from the group!), Julian Jones, Alan Kersey, Ralph Tatam and others, Dave would preside over vigorous discussions with Xiaoyi Bao, William Dove, Faramarz Farahi, Robert Griffin, Antonio Lobo, Tongyu Liu, Craig McGarrity, Trevor Newson, Yinong Ning, Chris Pannell, Ralf Pechstedt, Adrian Podoleanu, Yunjiang Rao, Jose-Luis Santos, Dave Webb, and many more. It was a vibrant and rich environment that Dave had created and I remember my time there with great fondness.

\section{The Photonics Research Laboratory, the University of Melbourne}

When I arrived at the Photonics Research Laboratory (PRL) in May 1993, Rod Tucker had already assembled the key members of the group: Don Hewitt, Hai Feng Liu, Arthur Lowery, and Dalma Novak. I was for the first time a postdoc, but not long after my arrival I regained my tenure as senior lecturer and in 1995 became deputy director of a world-class university laboratory in optical communications - only the major telco labs (Bell Labs, NTT and BT) surpassed the level of infrastructure that Rod had assembled. The PRL was the Melbourne node of the Australian photonics cooperative research center, led by Mark Sceats, and headquartered at the University of Sydney in the optical fiber technology center founded in 1990 by Simon Poole from Southampton. Again, these were heady days of the deployment of the optical amplifier and the first telecommunications applications of fiber Bragg gratings, with major contributions made by Francois Ouellette and Peter Krug in Sydney and Tom Stephens at Telstra Research Labs in Melbourne. I had crossed from Physics into the world of electrical engineering.

When I arrived in Melbourne, Rob Griffin (at Kent) and I had still much to work out in relation to noise. Rob was finalizing his $\mathrm{PhD}$ and I hired Graeme Pendock to work with me on CDMA. Graeme was a standout recruit. He had it all - lab skills, maths, modelling, a knack for finding where his problem had been largely solved by someone else working on something quite different, and an obsession with cracking a problem. $\mathrm{PhD}$ student Mike Cahill joined us and soon we had demonstrated multigigabit-per-second performance and four-channel operation (Fig. 4) - which was the best performance reported for a number of years [39, 40]. However, by mid 1995 Graeme, Robert and I had gotten to the bottom of the photonic CDMA story, and decided we would put it to bed. There was simply no effective way of getting around the noise generated by incoherent interference of multiple piled up pulses. Graeme and I published in 1997 a

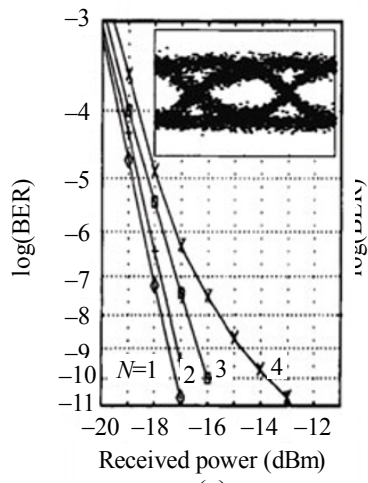

(a)

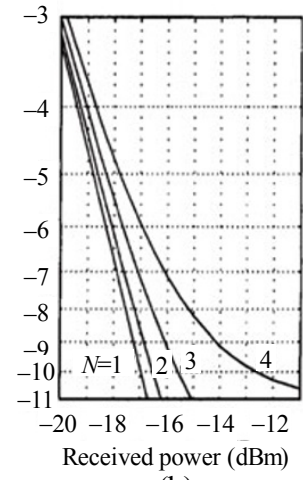

(b)

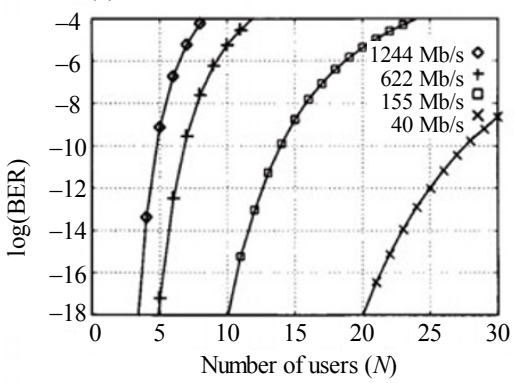

(c)

Fig. 4 Measured and calculated performance (upper left and right, respectively) of a CDMA system, and its limited network performance (lower). After [38]

thorough analysis of the problem [41] and a performance analysis for CDMA [42], and with Rob, 
we wrote an invited review of the field in the same year [38] and then let it go. History would suggest we made a sensible choice because the technique has not made a mark in optical communications in the intervening years.

Generation of broadband light was at the heart of using optical coherence as a discrimination mechanism in photonic CDMA, so it was natural that I take an interest in its generation via amplified spontaneous emission and optical amplification. Slicing broadband light had been proposed in the $1980 \mathrm{~s}$ as an effective means of low-cost wavelength-division multiplexing (WDM) [43]. I started working with my $\mathrm{PhD}$ student Warwick Holloway on this and we were one of the first groups to demonstrate how different dopants in erbium-doped fiber could be employed to produce, in our case, a flat spectrum for sliced WDM channels [44] and not for gain flattening per se [45] - this work was presented postdeadline at the the Optical Society of America's Optical Amplifiers and Their Applications Topical Meeting in Breckenridge, Colorado in 1994 (Fig. 5). We then showed this source could be sliced giving unprecedented high-bandwidth performance [46]. Postdoc Adrian Keating joined Warwick and I to take this to $2.5 \mathrm{~Gb} / \mathrm{s}$. Spectrally slicing amplified spontaneous emission suffered from precisely the same beat noise as did photonic CDMA, but Adrian came up with a nice way to reduce its impact by feed-forward optoelectronic noise cancellation, which we demonstrated in 1995 [47, 48]. We also demonstrated that a Fabry-Perot laser operated below threshold coupled to a flat amplifier could provide 30 channels each operating at $622 \mathrm{Mb} / \mathrm{s}$ [49] and showed how such a source could be used to build a single-source WDM ring network [50].

In the meantime, Graeme Pendock had worked out the performance of these systems [51], utilizing key results from Personick [52] and Marcuse [53]. In particular, we included the subtle effect of the fiber dispersion on reducing the optical beat noise-limited signal-to-noise ratio. Subsequently, in a beautiful but largely unrecognized piece of work, we showed that not only did dispersion reduce this signal-to-noise ratio, but it also varied across a bit period [54].
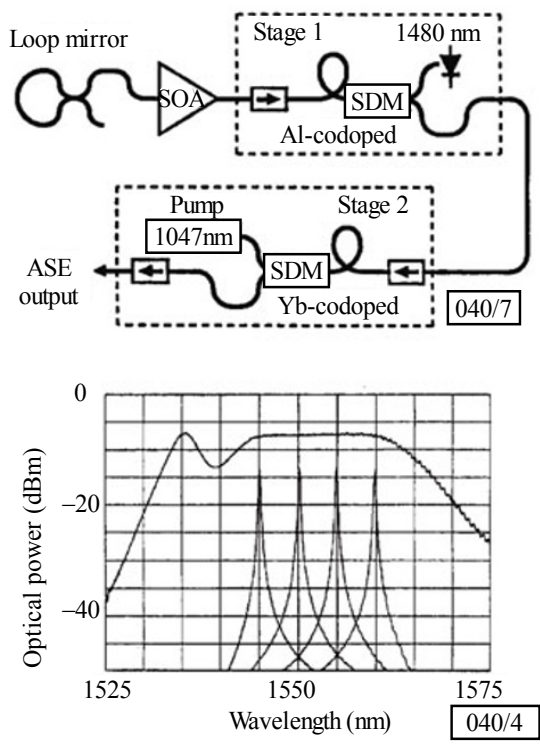

Fig. 5 Circuit (above) and output (below) of a wavelength-flattened broadband source with four spectrum-sliced channels. After [44]

Throughout this period, I had maintained an unhealthy interest in the properties of semiconductor lasers, especially under gain switching, and published a number of papers in this area beginning with the noise and coherence properties of Fabry-Perot lasers elegantly worked out by Robert Griffin at Kent [55], and including data transmission at high bit rates [56] and the reduction of timing jitter in gain switching by continuous-wave (CW) injection [57].

During my period in Melbourne, I was privileged to interact with some of the great figures of optical communications. Beyond the group in Melbourne that included Jon Lacey, it was wonderful to interact with many other fine Australian colleagues, including John Love, Barry Luther-Davies, Simon Poole, Mark Sceats, Tom Stephens, and Martijn de Sterke. As Far East Liaison to the Optical Fiber Communications Conference for a number of years, I had the privilege of meeting some of the great figures during this historic period 
of optical communications. I remember with particular fondness Andrew Chraplyvy, David Cotter, Nick Frigo, Chuck Henry, Ken Hill, Bob Jopson, Mike O'Mahony, and Rajiv Ramaswami.

\section{The University of Western Australia - the Optical+Biomedical Engineering Laboratory}

May 1996 saw my arrival for a fresh start at UWA - with no laboratory and no group. The next two years were spent, firstly, clearing the pipeline of research in communications $[25,41,42,48,49,51$, 54, 56], including our CDMA review [38]. Secondly, the lab was established in 1997 - including a generous donation of equipment from the closure of the Telstra Research Labs in Melbourne, through the generosity of Rob Ayr. Thirdly, I set about learning a new field - biomedical optics and biophotonics. Studying aspects of medicine, physiology and cell and molecular biology was exciting as I had no prior knowledge. I firstly noticed optical coherence tomography (OCT) sometime in the 1993-1994 period, not long after the landmark paper in Science [58]. In 1995, I ran the technical program for the Australian Conference on Optical Fiber Technology, held on the Gold Coast, and took the opportunity to invite Eric Swanson from MIT, one of the key members of the Fujimoto group, who founded optical coherence tomography (Eric later co-founded the optical networks company Sycamore Networks and Graeme Pendock was one of its first employees). Discussions with Eric left me convinced it would be a fascinating area. Optical coherence tomography (Fig. 6) had many roots, as explained in a book chapter my $\mathrm{PhD}$ student Timothy Hillman and I wrote during my 2003 sabbatical [59], including low-coherence interferometry and high-resolution optical time-domain reflectometry, subjects already close to my heart. It seemed a natural fit.

During 1997, I wrote many grant applications, and with funds beginning to flow, hired my first postdoc at UWA, Andrei Zvyagin, in mid 1998 which marked the official start date for the lab - the
Optical+Biomedical Engineering Laboratory came into existence. Andrei had an excellent pedigree, including references from Russian Nobel Laureate (for the laser) N. G. Basov and nanophotonics expert M. Ohtsu at the University of Tokyo. Over the next five years, Andrei would apply his considerable energy and enthusiasm to helping me establish the group. We set about building a research program centered on optical coherence tomography, which has remained the group's focus over the last decade.

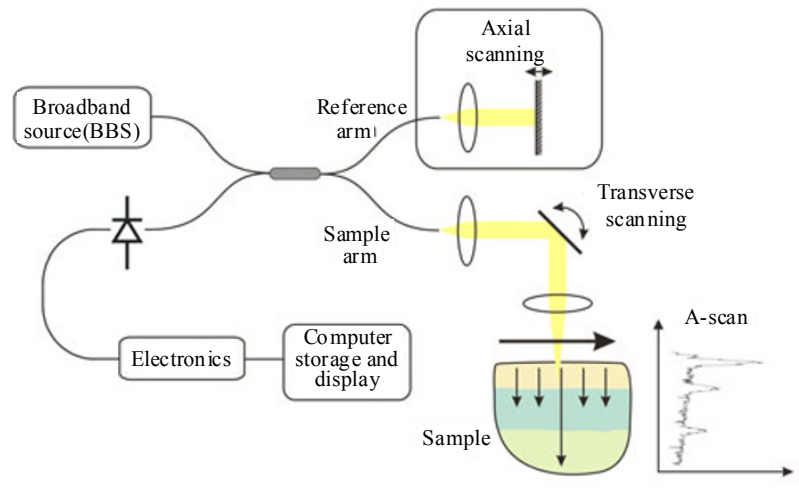

Fig. 6 Schematic diagram of the simplest OCT system.

\subsection{Optical coherence tomography: performance limits and image formation}

Since entering the field, the physics of image formation in turbid media has intrigued me. Low-coherence interferometry has the exquisite ability to select only the "ballistic" or nearly ballistic portion of the wave that has propagated directly to the target and back, with very high discrimination. It uses the far superior temporal resolution of optical coherence compared with short pulses. Since the coherence time depends on the spectral bandwidth, only in the few femtosecond regime can transformlimited pulses attain comparable resolution. To understand the fundamental limits set by absorption and dispersion of light on the axial resolution of optical coherence tomography, we conducted an analytical study published in 2005 [60]. Absorption is largely by water, since it makes up $60 \%-80 \%$ of biological tissue, and it largely accounts for the dispersion too (Fig.7). Absorption only becomes significant at and beyond the $1.3-\mu \mathrm{m}$ wavelength 
band, setting ultimate limits on resolution that cannot be overcome - the spectrum is distorted and the related image information is lost. Dispersion, in principle, can be perfectly compensated, but our work showed that the resolution was much more sensitive to dispersion than in optical communications, and that compensation of multiple orders would be required to deal with it effectively. Interestingly, the zero of dispersion for tissue is close to $1 \mu \mathrm{m}$, not $1.3 \mu \mathrm{m}$ as it is for silica glass. Optical coherence tomography is a differential technique and so it is the differential dispersion, i.e., the difference in dispersion between the interferometer arms, that matters. This is static for the instrument, but varies with scan depth in the sample. Earlier, OBEL postdoc Elwyn Smith had shown an elegant way to dynamically compensate for this sample-dependent dispersion [61].

Improving the axial resolution of optical coherence tomography by increasing the source optical bandwidth was a strong driver of research for many years, and the emergence of the supercontinuum source [62] was a tantalizing development. Such sources do not have ideal spectral shapes and so can produce poorer resolution than might be expected from their wide bandwidth and a great deal of side-lobe structure in the wings of their response functions. Spectral-domain optical coherence tomography overcomes this problem via access to the complex spectral amplitude, which can be shaped to improve the response function. Elwyn Smith demonstrated such shaping in elegant experiments on prototype supercontinuum sources conducted at the Communications Research Laboratory, Tokyo, Japan [63, 64] (Fig. 8). Similar work was done shortly after by Johannes De Boer's group [65] and then supercontinuum sources were pushed into the sub-micron resolution regime by Drexler's group [66]. The connection to the laboratory in Tokyo had been established through Ken-ichi Kitayama, an optical CDMA researcher, and Robert Griffin, Julian Armstrong, Elwyn Smith and I all visited this lab in the late 1990s [67]. It was a fascinating and memorable window into Japanese research and culture and I made some great friends, especially Naoya Wada, Tomiyama-san and Ken-ichi himself, now at Osaka University.

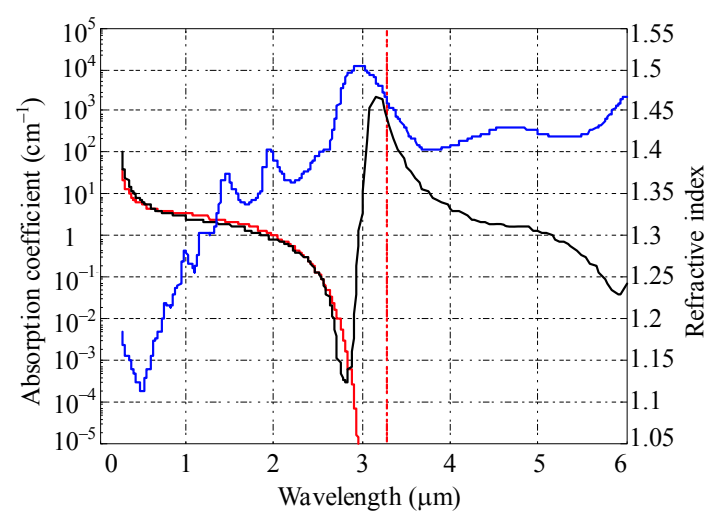

Fig. 7 Absorption (upper curve) and refractive index spectrum (lower curve) of water (the overlaid curve plots data from a model in the near infra-red wavelength range and the dotted line is its asymptote) [60].

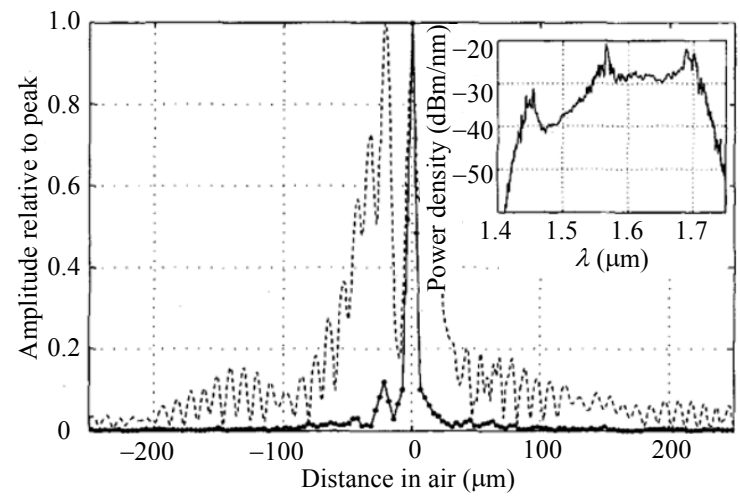

Fig. 8 Spectrally shaped (solid) and as-recorded (dashed) responses for a close-spaced (by $22 \mu \mathrm{m}$ ) strong/weak reflector pair, with the supercontinuum source spectrum in the inset (the weak reflector $(-20 \mathrm{~dB}$ reflectivity) is revealed after spectral shaping) [63].

Being able to detect so-called single scattering at high resolution, i.e., having a signal, does not guarantee faithful image formation. There are three main factors at play. The first is simply phase distortion - if you put a large-scale phase element in an optical beam, its effect is profound. This means, for example, that images of subsurface structures can be severely distorted by small variations in the surface topography. Refractive index matching is an effective solution to eliminate these effects, but at 
the sacrifice of non-contact imaging. This is an aspect of optical coherence tomography that is self-evident to some and invisible to others. We are revisiting it at the moment in relation to a project in imaging scars being undertaken with the prominent Australian burns surgeon, Dr Fiona Wood.

The second factor in image formation in optical coherence tomography is its coherent basis resulting in the formation of speckle. In this, it shares common underlying physics with other coherent imaging modalities, notably ultrasound. The appearance of the images in the two modalities is very similar, even if their resolution varies by more than an order of magnitude and the tissue features giving rise to image contrast are different. Speckle was studied extensively in the 1970 s by researchers such as Joseph Goodman [68] and Christopher Dainty [69]. Joseph Schmitt was the first to seriously examine the topic in optical coherence tomography [70]. Speckle has been widely regarded as a distorting influence, but my interest was in what, if any, sample-dependent information it carries. This interest was kindled prior to and during my sabbatical in Florence in 2003, and I had a number of stimulating discussions on the topic with Steve Jacques, during his stay with us in Florence. Timothy Hillman, in his virtuoso style, worked out the theory and eventually the experiments caught up. We showed that under the condition that the effective number of scatterers in an image voxel satisfied the central limit theorem, the speckle did not depend on the sample at all and its contrast was constant. When the sample becomes less scattering or the voxel volume decreases sufficiently, the speckle contrast increases quickly and reflects the scattering properties of the sample [71]. Much more elegant analysis remains unpublished in Timothy Hillman's excellent $\mathrm{PhD}$ thesis. More recently, we succumbed to the "speckle is bad" philosophy, and have demonstrated how tissue mechanical properties can be used to reduce it $[72,73]$.

The third of the trio of factors impacting on optical coherence tomography image quality is multiple scattering. Eventually, the single-scattering component is overwhelmed by multiple scattering residual components of the optical beam with the same path length as single scattering, but not correlated with the sample voxel being probed. Multiple scattering is not divorced from the wavefront distortion caused by phase perturbations described above. When the phase shifts are spatially large, we refer to "wavefront distortion", as is done in microscopy [74]. When they are small and numerous, we refer to multiple scattering. In fact, the phenomena form a continuum. Multiple scattering is very evident when a thin dense scatterer is present. Good examples are thin paint layers, paper and plant seed coats [75]. But it is also evident in many samples in a less obvious way, and it would be valuable to know a priori when it was present in a given image.

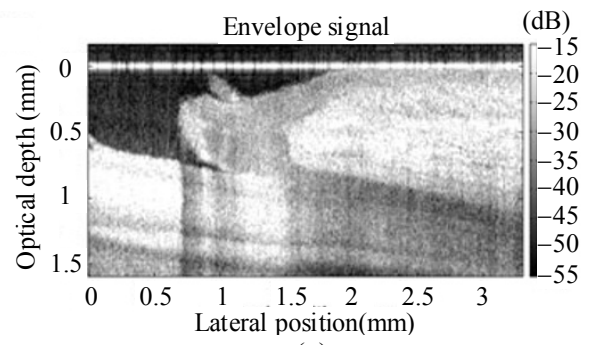

(a)

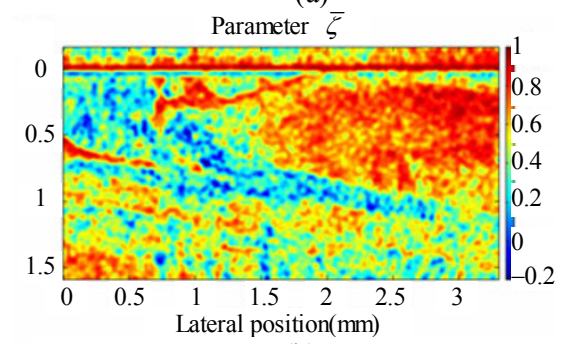

(b)

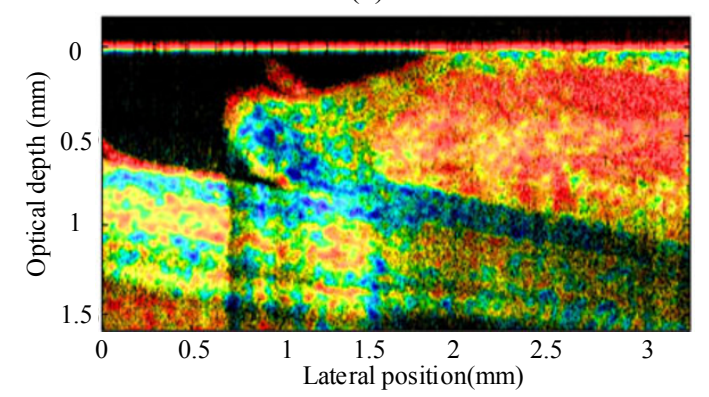

(c)

Fig. 9 Human nailfold imaged with (a) OCT, (b) multiple scattering depolarization metric, and (c) their overlay [76].

We began to examine this problem by studying the connection between polarization state and 
multiple scattering (Fig.9) and more recently examined the link to angular correlation of speckle (Fig. 10) and developed several metrics to connect the two $[76,77]$.

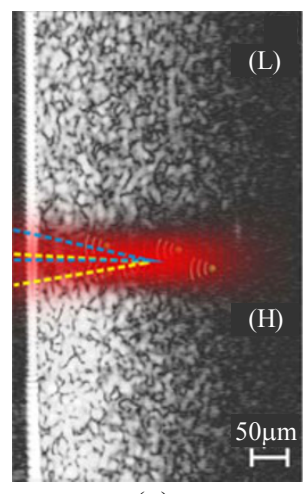

(a)

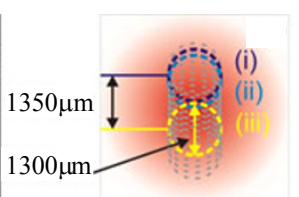

(b)

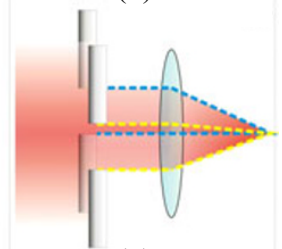

(c)
Fig. 10 (a) Angle dependent acquisition of 2D OCT B scans using a detection iris shown in (b) and (c) [77].

\subsection{Optical coherence tomography: technology and techniques}

\subsubsection{Frequency-domain optical delay lines}

Optical delay lines formed a key part of my University of Kent experience [12, 14-16, 78]. In optical coherence tomography, the issue is one of scan speed. Video frame-rate 2D imaging with more than 500 pixels per dimension requires tens of meter-per-second scan rates (even if only over a few millimeters). Such rates are unfeasible using a linear scanning mirror. Two means, both dependent on the optical frequency domain, have been established to solve this problem. The first is to vary the optical delay by imparting a linear phase shift in the optical frequency domain, equivalent to a time shift in the autocorrelation domain. Scanning can then be achieved by changing the phase ramp. This was first demonstrated by Heritage and colleagues in 1993 [79] for application to pulse autocorrelation, although its genesis was much earlier in the picosecond and femtosecond pulse shaping research of the 1980s: see, for example, [80]. It was applied to optical coherence tomography by Gary Tearney et al. [81] and pushed to video rates by Andrew Rollins and colleagues in 1998 [82]. Meter-per-second rates could be achieved because a tilting galvanometer mirror could scan the necessary few degrees at $\mathrm{kHz}$ rates. Robert Griffin had built these devices in the early 1990s [30] and demonstrated their functionality [31], so it was engaging to re-examine this complex device (Fig. 11). Our interest was firstly in long-delay scanning because we had identified an application in hollow organ profiling, to be described later. Dilusha Silva demonstrated 23-mm delay using the device in 1999 [83].

The frequency-domain optical delay line has the delightfully tutorial property of allowing independent modification of phase and group delay, and we demonstrated its use for the first time as an achromatic pure phase modulator in 2001 [84]. We then demonstrated its ability to perform scan-dependent dynamic sample dispersion compensation [61], and published the most comprehensive account of its properties in 2003 [85] (Fig. 11).
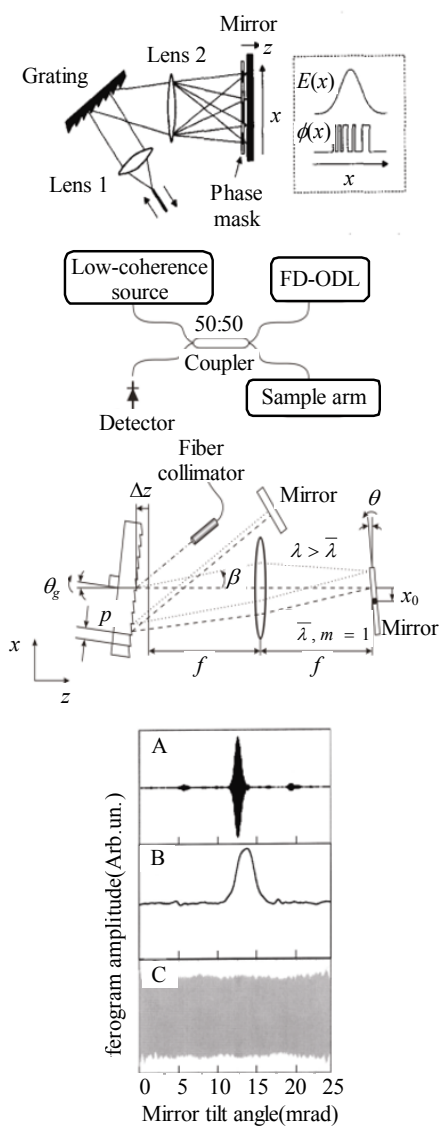

Fig. 11 Delay line device constructed in 1993 (upper) and in 2003 (middle) [59] and response functions operating for group and phase delay equal A, zero phase delay B, and zero group delay C. [85] 


\subsubsection{Contrast and refractometry}

It has always been apparent that optical coherence tomography would benefit from enhanced contrast, and OBEL has been active in examining how this may be achieved. Our first interest was in refractive index measurement. Robert Barer showed in the 1940s and 1950s that refractive index was a surrogate for "ground matter" in cells - the "stuff" left over after water was removed - mainly proteins [86]. Tearney et al. firstly showed how optical coherence tomography could measure refractive index (although it measured group index rather than phase index), but their method involved a lengthy scanning procedure [87]. Postdoc Sergey Alexandrov introduced the technique of creating a confocal response function with two peaks and measuring its length with OCT [88]. This paper is notorious at OBEL because, after being correct in the galleys, mysteriously it was published in Optics Letters under the erroneous title "Bifocal-optical coherenc erefractometry of turbid media". This technique produced an average refractive index measured over the two peaks which could be used to readily scan a sample or make a point measurement [89]. We also implemented a version of this measurement in a needle format to access solid tissues [90]. The needle version came about because Adam Zysk, then a $\mathrm{PhD}$ student in Stephen Boppart's lab at the University of Illinois at Urbana Champaign, was working on refractive index tomography and noticed our work. He visited us for a period and I challenged him and Matthew Leigh, my $\mathrm{PhD}$ student, to come up with a needle for measuring refractive index. They did, and subsequently the Boppart group came up with another nice idea on how to do so [91].

Our second approach to enhancing native OCT contrast has been to investigate the other optical properties of tissues - extinction (scattering and absorption) coefficients, anisotropy and even mechanical properties (see next section). Last year, we published a study examining images of the extinction coefficient in optical coherence tomography of human lymph nodes [92]. In essence, trading off the third (depth) dimension in an attempt to improve the sensitivity to detecting cancer. In fact, what we showed was increased sensitivity to residual benign tissue, but the result was a promising start and the work is ongoing.

\subsubsection{Optical coherence elastography}

More recently, OBEL has been active in probing the elastic properties of tissue with OCT - so-called optical coherence elastography [93-96]. The motivation for this is the simple observation that physicians use "feel" to diagnose tissue and many "lumps", notably tumors, are harder than surrounding tissue. A second motivation is drawn from cardiovascular disease. Atherosclerotic plaques may be fibrous or lipid rich, with vastly differing mechanical properties. If lipid-filled, plaques can be prone to rupture causing stroke. This work had its genesis in the refractive index measurement published in 2003 and Sergey Alexandrov and $\mathrm{PhD}$ student Steven Adie labored on it for several years without success. Steven ultimately completed his $\mathrm{PhD}$ and departed for the Boppart lab and left it to postdoc Brendan Kennedy to push this research forward. It turns out elastography has been extensively investigated, based on ultrasound [97] and, to some extent, using magnetic resonance imaging [98], and commercial ultrasound instruments are employing it. Joseph Schmitt was the first to propose and demonstrate it in optical coherence tomography in 1998 [99]. His work and that of most others was based on static or very low frequency perturbation of the tissue from the outside and measuring its effects using speckle tracking in consecutive OCT B scans. From the outset, we have been interested in dynamic excitation outside of the viscoelastic regime - at low frequencies tissue displays a lag in its response. We borrowed from a classic David Jackson technique of looking at interferometric Bessel components arising when an 
interferometer was phase modulated [93]. From there, we demonstrated the first practical in vivo results by building a ring-based transducer to image and excite from the same direction external to a tissue [94]. Since then, we have continued our strong collaboration with Stephen Boppart's group and extended optical coherence elastography to examine the acoustic spectrum of mechanical excitations [95] and to image in three dimensions [96] (Fig. 12).
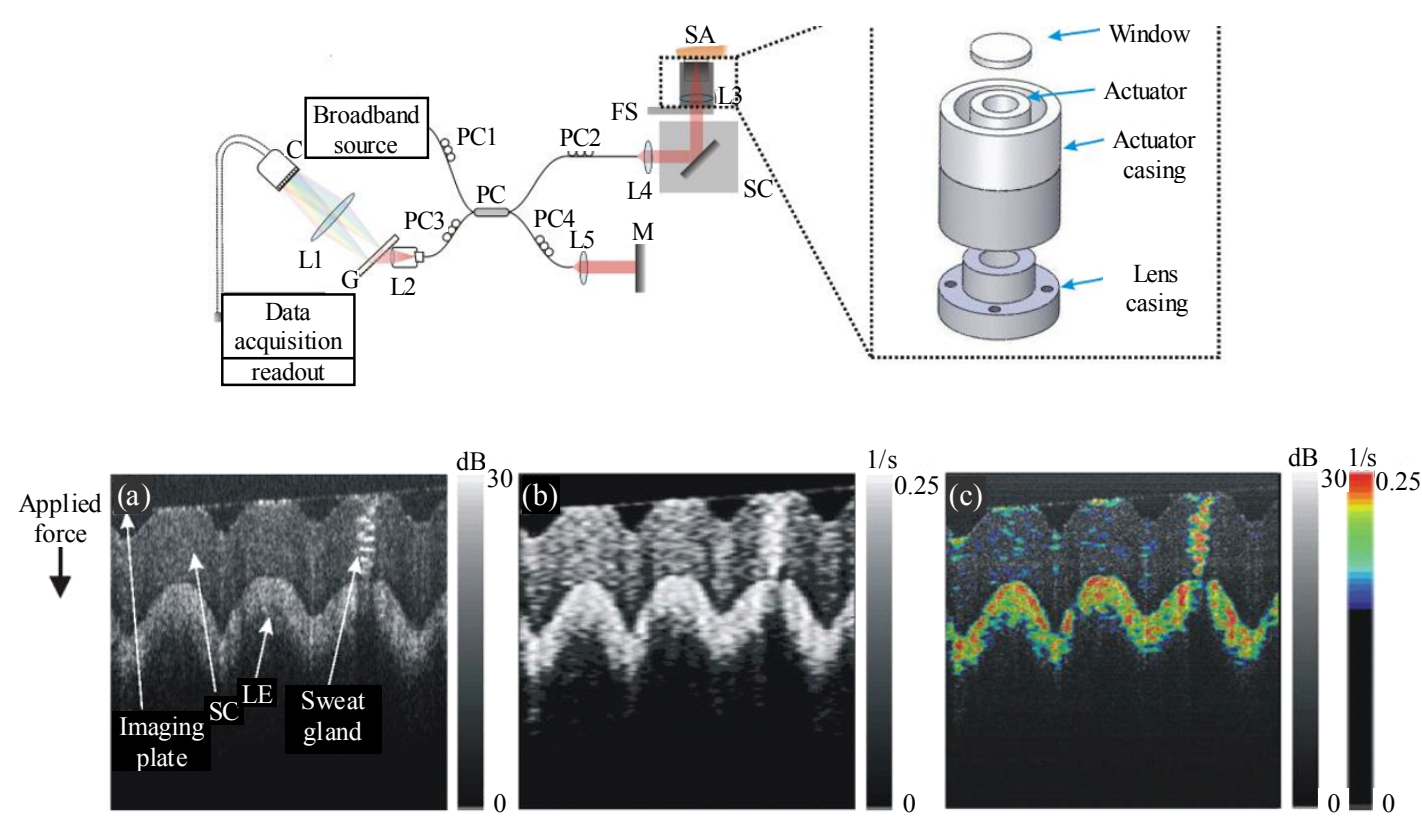

Fig. 12 Optical coherence elastography setup (upper) and skin images: (a) OCT, (b) OCE, and (c) both overlaid [96].

It is a curious fact that even though optical coherence tomography has been a research field for 20 years, it is not possible to purchase a standard three-dimensional reference target, such as the 1951 United States Airforce Target in two dimensions. Multiple layers of adhesive tape have been the de facto norm. We have been interested in tissue-mimicking phantoms for some time, both for the pragmatic reason of being able to validate a system's performance over time and because we are also interested in phantoms with particular elastic as well as optical properties. Brendan Kennedy developed an innovative fibrin phantom recently [100]. Fibrin is related to the blood clotting agent thrombin. OBEL researcher Andrea Curatolo, working with Brendan, and colleagues at the Australian National Fabrication Facility, recently realized the first true three-dimensional phantom for optical coherence tomography, using a versatile lithography platform (Fig. 13) [101].

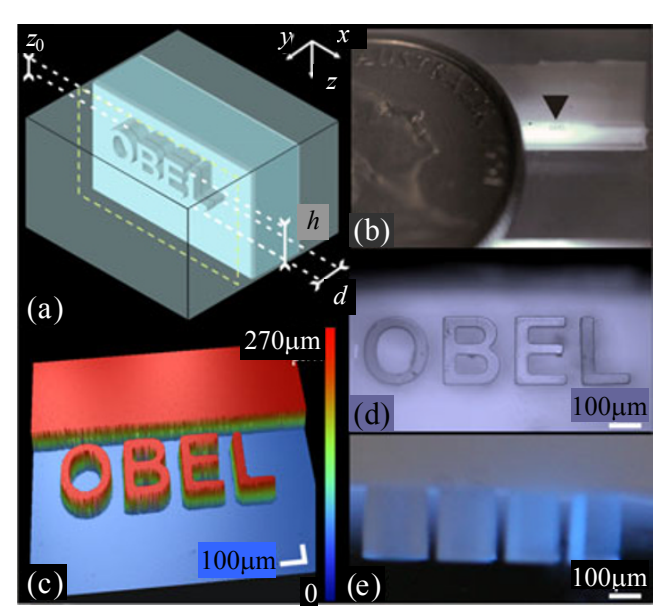

Fig. 13 "OBEL" phantom: (a) schematic, (b) photomicrographs next to Australian 5c coin and (d), (e) from two sides, and (c) measured surface profile.

\subsubsection{Microscope in a needle}

Since completing our first needle refractive-index probe in 2007, we worked hard as a group to establish a viable needle technology. Optical coherence tomography is intrinsically 
limited in depth penetration, which although highly variable, rarely extends beyond $2 \mathrm{~mm}$ in most tissues, restricting access to structures deep in tissues. Xingde Li, working in the Fujimoto group, was the first to explore this with optical coherence tomography in 2000 [102]. In the following years, the challenges of imaging in such a small format restricted progress. Meanwhile, researchers in the field of neuroscience had similar goals in imaging deep into mouse brains with multiphoton microscopy [103]. The advantage of optical coherence tomography is that it has lower specification optical requirements compared with multiphoton microscopy, but of course it produces lower resolution images too.

Visiting intern Tobias Joggerst was the first to really make progress on building needles at OBEL, but researcher Bryden Quirk has since been the driving force, supported by many others in the group, notably Dirk Lorenser and Rodney Kirk. OBEL now has a powerful platform (Fig. 14) capable of translating a radially $3 \mathrm{D}$ scanning OCT needle probe to produce three-dimensional images [104] (Fig. 15) and many publications in the pipeline. Our current application targets are airways in mouse models in the study of airway diseases (see the next section below) and breast cancer tumor margin detection.

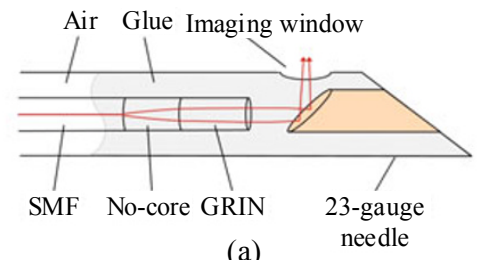

(a)

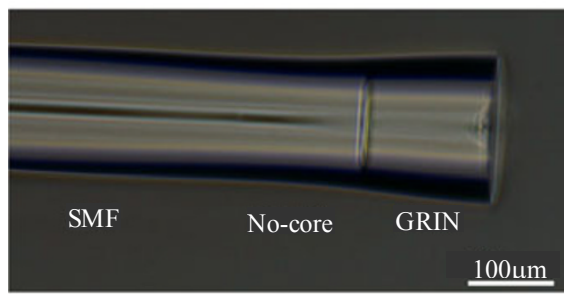

(b)

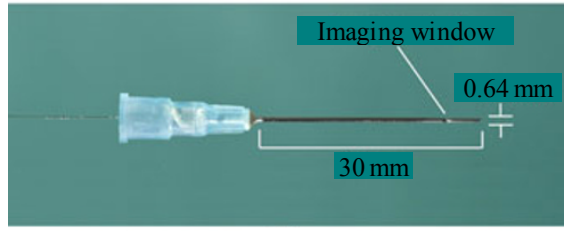

(c)

Fig. 14 OCT microscope-in-a-needle technology: (a) schematic diagram of needle design, (b) fused fiber optics, and (c) mounted in a 23-gauge hypodermic needle.
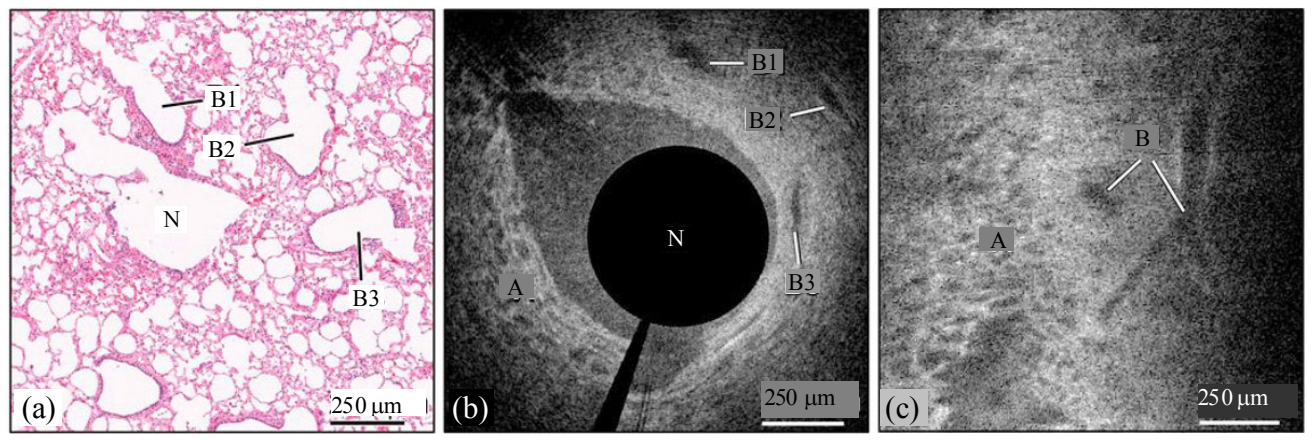

Fig. 15 Ex vivo ovine lung: (a) histology, (b) OCT cross-sectional, and (c) oblique images (N: needle hole; A: alveoli; B: bronchiole) [103].

\subsection{Optical coherence tomography: applications in medicine}

OBEL's strong linkages with medical and pathology researchers have enabled it to undertake vital benchmark OCT studies, e.g., on lymph nodes [105]. This was made possible through Robert McLaughlin joining the group in 2008. With his background in medical imaging, both academic and commercial, combined with his energy and charisma
Rob has very effectively driven the group in the clinical area. One of his first achievements was to write OCTView, enabling effective visualization and arbitrary sectioning of three-dimensional OCT data. At the time, good matches between images and histology were rare, and this is a vital precondition to effective engagement with a pathologist, and Rob brought Peter Robbins on board. With surgeon Christobel Saunders, we embarked on one of the 
first major baseline studies in optical coherence tomography imaging in cancer [105]. Cancer imaging had been cursorily examined for many times before in optical coherence tomography [106], and previous work has been led by Stephen Boppart [107]. Some substantial studies have been done, but none with strong histological correlation. Thus, such baseline studies have still to be undertaken. The images shown in Fig. 16 demonstrate excellent correlation and enable the pathologist to begin the process of identifying how morphology presents in a new medical imaging technology. Subsequently, other groups are beginning to acquire this much-needed capability [108, 109].

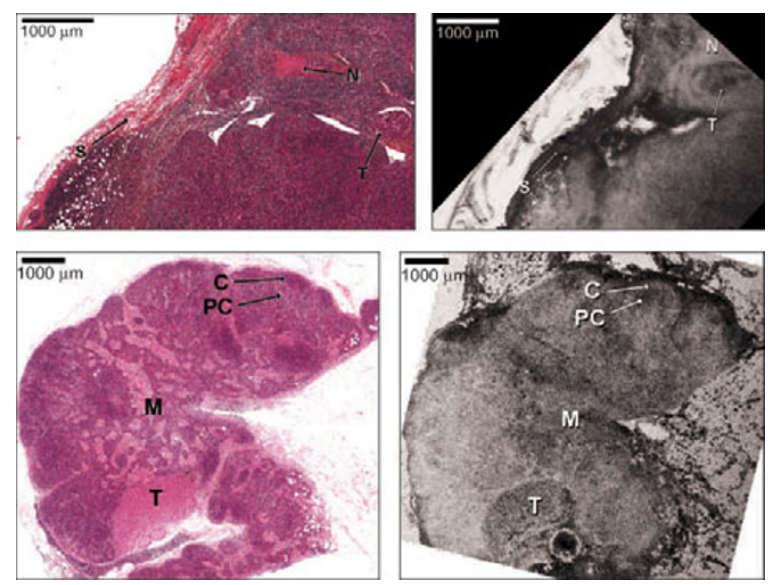

Fig. 16 Histology (left) and correlated OCT images (right) of an involved ex vivo human lymph node (T: tumor; $\mathrm{S}$ : stroma; $\mathrm{N}$ : necrotic metastatic deposit; C: cortex; PC: paracortex; M: medulla) [105].

One of our first major clinical collaborations, and the most extensive to date, has been in respiratory medicine [110-121]. This research began in the late 1990s when Peter Eastwood from Sir Charles Gairdner Hospital came to enquire if we knew anything about optical coherence tomography. Peter wanted to study the human upper airway during sleep because his major interest was in sleep apnea. Julian Armstrong, a very gifted honors student, and I began looking at how to do optical ranging in the upper airway - the range required was beyond 30 millimeters. We hoped to avoid using OCT and spent the first few years looking at frequency-modulation continuous-wave (FMCW) techniques - the precursors to Fourier-domain optical coherence tomography [122]. With the available sources, we simply did not have the frequency scanning range or speed at that time, and so reverted to OCT, and the frequency-domain delay line [83] (again!). With the help of Matthew Leigh, who proved to be an excellent instrumentation engineer, by 2003, we had built up the capacity to image the upper airway in vivo [110]. We called the early system "HOPS" - hollow organ profiling system, in deference to Australian beer drinking culture, and subsystems were known as MALT and ICE (Fig. 17). It was surprising how much signal one could detect at $20-\mathrm{mm}$ distance from the side-scanning rotating catheterized probe, even at very oblique surface angles - alas, we still could not see around corners (Fig. 18). Julian Armstrong finished an excellent $\mathrm{PhD}$ by publishing a landmark study on what I coined "anatomical" optical coherence tomography, to capture the fact that we were profiling hollow organ anatomy rather than probing its subsurface structure. By the time

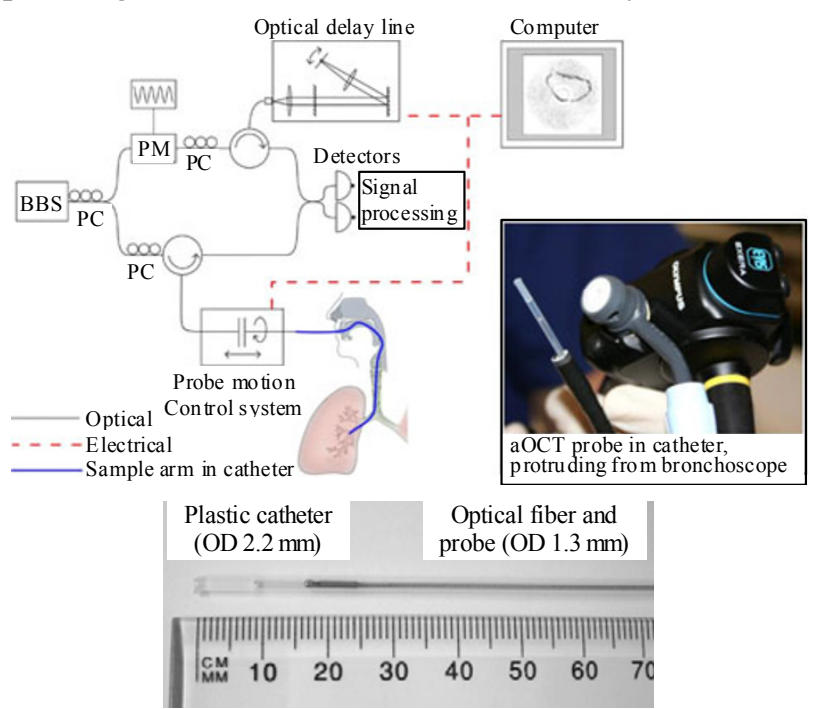

Fig. 17 Schematic diagram of the anatomical OCT scanner (inset: catheter (see photograph) protruding from commercial bronchoscope). After [117]

American English had been applied, it had become "anatomic" [111]. Matthew Leigh wrote a companion engineering paper describing the tool in more detail and surveying other potential applications [112]. Robert then wrote one of the 
Optical Society of America's first papers using the new 3D image data tool, allowing users to download and manipulate the data [113] and followed it up with an elegant example of gating, which made the front cover the Virtual Journal of Biomedical Optics [116]. Further supporting work independent tracking systems [123] has also been completed. Finally, an innovative fluid mechanics study of the upper airway was conducted by Tony Lucey's group at nearby Curtin University on the fluid dynamical performance of the upper airway resulted in a substantial work being published [124].

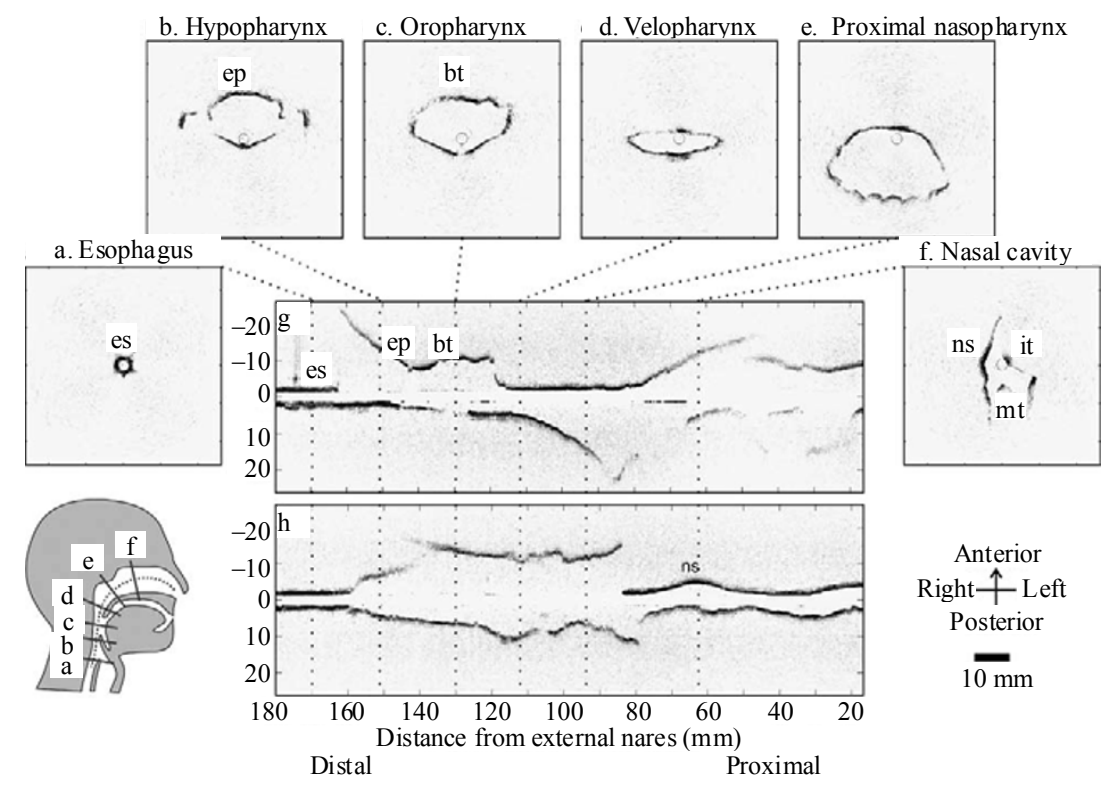

Fig. 18 Upper airway profiles in the normal human pharynx [111].

Led first by Julian Armstrong and then by Robert McLaughlin, we set about applying this tool with collaborators in Pulmonary Physiology at Sir Charles Gairdner Hospital in sleep research [114, 115], in basic airway physiology with Howard Mitchell's UWA physiology group [118, 119] (Fig. 19), and in the lower airway in an intraoperative setting. Physician and respiratory specialist Jonathan Williamson led applying anatomical OCT to the lower airway, his $\mathrm{PhD}$ research, and proved to be an outstanding collaborator in all ways [117, 119-121]. We found ourselves, for the first time, taking prototype instruments into the operating theater - both exciting and daunting (Fig.20). We conducted studies on intraoperative imaging of stenosis [125] and tracheomalacia [117], and performed a pioneering study of local compliance [121] that featured on the cover of the journal and in the editorial [126].
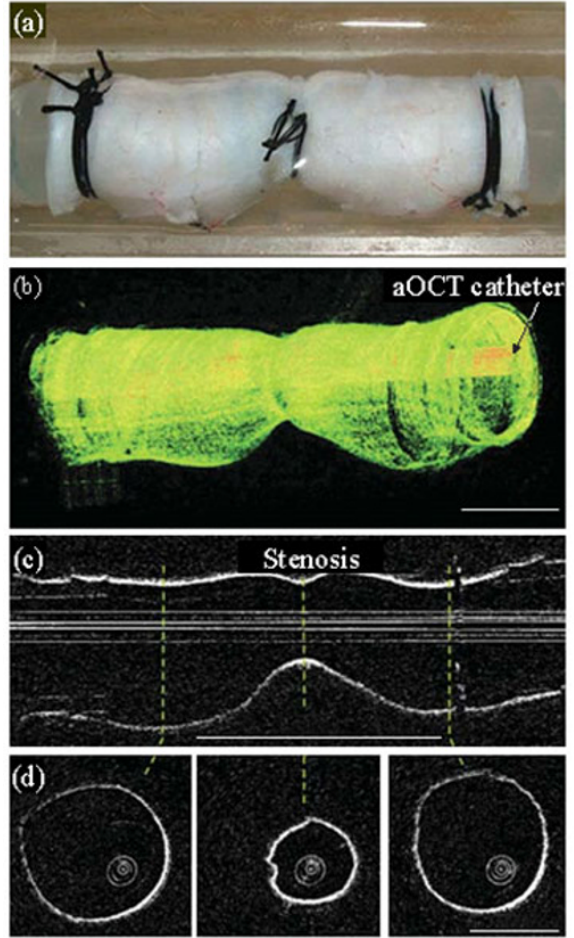

Fig. 19 Airway profiles from an explanted porcine trachea for airway physiology studies [120]. 


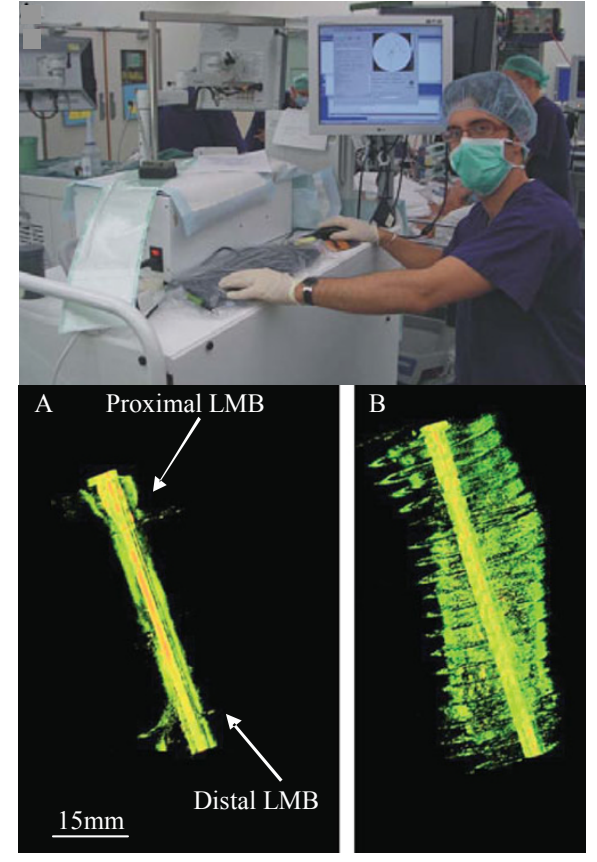

Fig. 20 Instrument and operator in theater (upper) and lower panels show lower airway before A and after B application of a stent. After [125]

\subsection{Other areas of research at OBEL}

\subsubsection{Tissue optics and optical clearing}

During our work on refractive index, and after reading Robert Barer's early work [86] and the protocols well known in histology to clear opaque tissues, I became very interested in improving deep-tissue imaging through optical clearing - the use of biocompatible agents introduced into living tissues to make them more transparent. Vargas from Welch's group had shown the remarkable transparency of mouse skin when a good deal of glycerol was injected subcutaneously [127]. The issue for optical coherence tomography is that simultaneously the source of signal (scattering) and degradation (also scattering) were reduced. This was not the case for fluorescence [128] or multiphoton microscopy, and so during my 2003 sabbatical in Florence with Francesco Pavone and Giovanni Zaccanti, Francesco's PhD student Riccardo Cicchi and I set about demonstrating this [129]. This work featured prominently in Valery Tuchin's book entitled "Optical Clearing and Blood" [130].
Elucidating the optical properties of tissues continues to be a fascinating field of study. Tim Hillman and I had followed, in particular, much of Schmitt's work in this area: the fractal properties of tissue scattering [131]; attempts to model the image formation process [132], and the formulation of a discrete particle model based on Mie theory [133]. One of the assumptions implicit in Schmitt's model was that the discrete scatterers did not interact. This made the Mie theory calculations tractable, but did not seem a very apt description given the continuum of scatterers in most biological systems. $\mathrm{PhD}$ student Dirk Schneiderheinze and Tim undertook a study using a modified Mie theory code that includes this interaction and showed, for the first time in tissue, the significant resulting differences [134]. Figure 21 shows an example of the particle distribution used in the model.

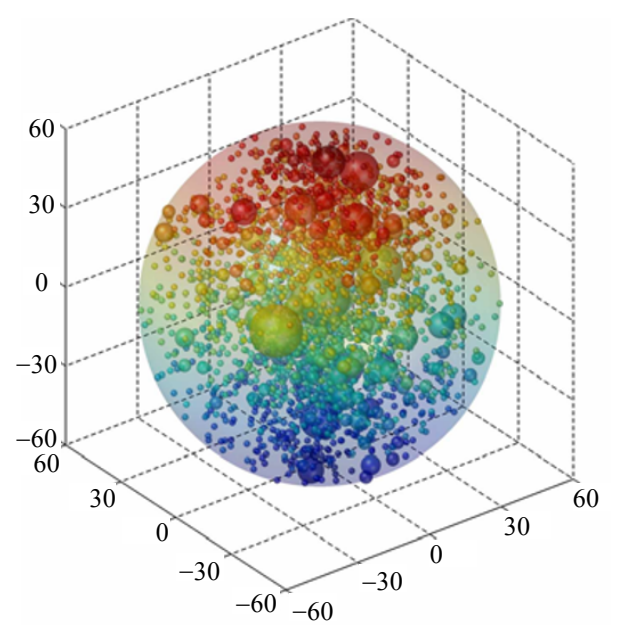

Fig. 21 Visual representation of particle fractal aggregate in the discrete particle model of tissue [134].

\subsubsection{Diffuse reflectance spectroscopy and skin cancer}

Every researcher has a "bête noir" and mine was melanoma. Soon after starting in biomedical optics in the late 1990s, I decided it would be a good idea to work on noninvasive diagnostics for skin cancer melanoma in particular. Australia leads the world in rates of incidence and a tool for early diagnosis by physicians would help patient prognoses. Unaided visual examination of pigmented lesions by a physician is the most common technique, but studies 
had reported unsatisfactory diagnostic accuracy compared with the gold standard histopathology, ranging from $56 \%$ [135] to $85 \%$ [136] with high inter-physician variability. Thus, the tool had to be sufficiently low cost to be available in general practice. I had read a lot about multispectral imaging, but the tool had to be lower cost than that. We decided on diffuse spectroscopy - based on arrays of large-core multimode fibers (Fig. 22).

In 1998, I was awarded a small grant from the Western Australian Cancer Council and put the team in place: Dr Peter Heenan, a cutaneous pathologist world-renowned for his expertise in melanoma, enthusiastic dermatologists Christopher Quirk and Christopher Clay, and a very bright graduate student, Kirrily Wong. Then, in 2000, I was awarded a major research contract to push the commercial side of noninvasive skin cancer diagnostics and Skin Cancer Analysis Technologies Ltd. came into being. With more than $\$ 1 \mathrm{M}$, I assembled a large team that rolled out a large study involving more than 15 local dermatologists and general physicians. A key aspect was that we needed to correlate the location of the fiber probe with histology. We recorded data on hundreds of lesions and assembled an extensive database (Fig. 23).

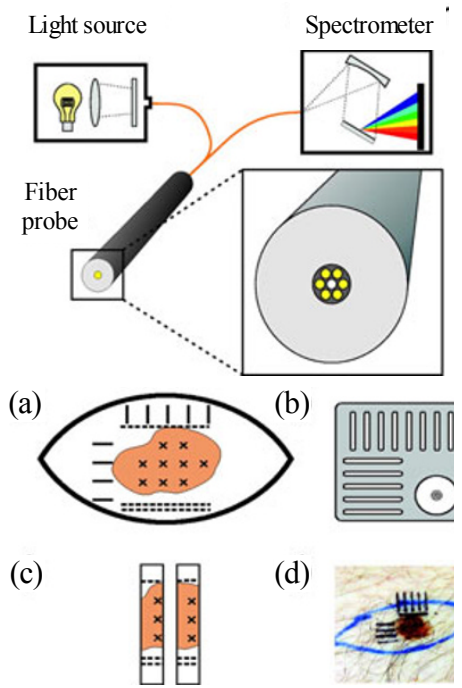

Fig. 22 Fiber-probe based diffuse reflectance spectroscopy of skin cancer (above) and method to co-register position of the measurement and histology (a)-(d). After [137]
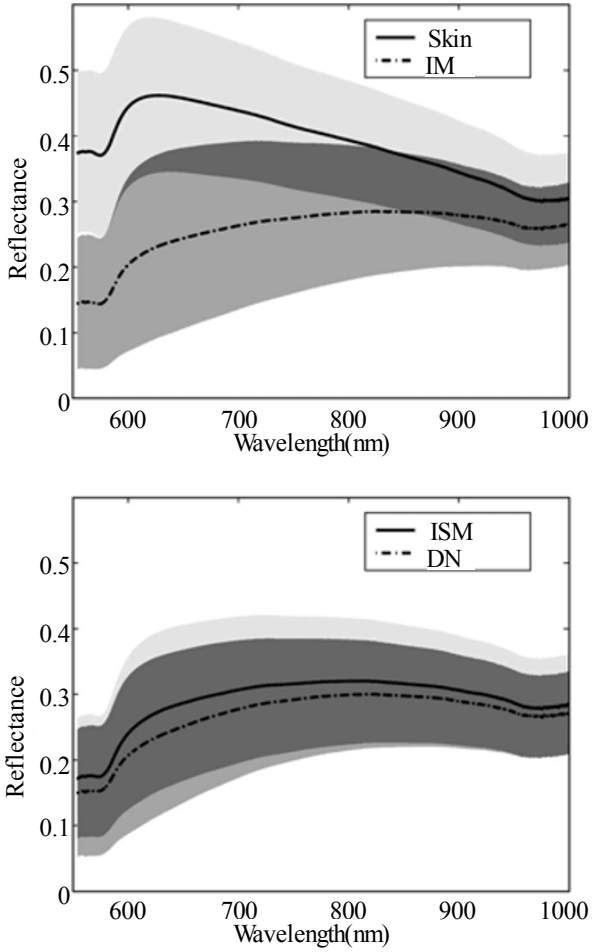

Fig. 23 Average skin spectra and their variance for: normal skin; IM: invasive melanoma; ISM: in situ melanoma; DN: dysplastic nevus [137].

This was where the challenges set in. Establishing multiple instruments that could record the same spectra interchangeably proved challenging - Ian Walton, on "abbatical" from a Silicon Valley biotech, was not surprised. Recording spectra from skin turned out to depend on pressure and probe angle - we designed a pressure sensitive probe tip. Tissue shrinkage during histology processing turned out to be variable and significant, thwarting our attempts to correlate probe position with histology. Kirrily Wong turned in a fine Masters thesis, but stalled in her PhD research. Bruce Murphy, a very gifted student, stepped into the breach and did much good work, but became distracted by other projects. Then, the company, realizing that commercialization was going to take time, pulled out. Soon, the large team shrunk to Bruce and I. Shell-shocked, in 2003 I took sabbatical leave in Italy. Bruce analyzed our data and wrote one excellent paper published in 2005 [137]. This was the most expensive paper I have ever produced, and Bruce did not go on to finish his $\mathrm{PhD}$, but instead joined Google in 
Switzerland. In one last hurrah, honors student Hannah Joyce worked on the project in 2005 and did some excellent modeling on the probe and tissue-optics models of melanoma. She stayed on afterwards to work on a paper, which she duly drafted, but it was never submitted. Hannah has gone on to excellent things in semiconductor device research.

I learned many things from this fascinating, well-directed, but unsuccessful research. Primarily, there is danger in empirical research - our probe did not work well, and the empirical study conducted, like all other empirical studies (and commercial products!), did not teach us where to go next. I learned that it was better not to hire than to hire the wrong person for the job; I learned the abject difficulty of clinical studies; and I learned the danger of depending on commercial funding - many valuable lessons. I learned much but achieved little melanoma had defeated me.

\subsubsection{Digital Fourier holography}

It would not be unreasonable to call Sergey Alexandrov "Mr Holography". Sergey joined us in 2001 from Belarus but hailed from St Petersburg. Although he did not have so many papers, his career in Russian industry had led to dozens of patents, mostly in holography. By the time I returned from sabbatical in 2004, Andrei Zvyagin had left the group and Sergey was at somewhat of a loose end. Steve Jacques was visiting us at the time and we had a sabbatical visitor Geoff Swan, who had been a cricket guru at the University of Kent during my time there. Geoff now held a position at Edith Cowan University in Perth. Steve suggested Geoff tackle a problem in Fourier optics related to paper published in 2001 by Boustany et al. [138], who had used a simple two-aperture filter in the Fourier plane to discriminate microscopic particle size in a microscope. I asked Sergey to work with Geoff, and sure enough, Sergey came up with a holographic solution. I got Tim Hillman involved on the calculation/analysis side and the result was a very nice paper in 2005 [139]. Sergey and Tim showed that you could deduce particle size by mapping the complex angular scattering spectrum using Fourier holography. In a single hologram, without resolving the scatterers themselves, you could deduce their size. Thomas Gutzler, who was an intern in 2002, returned as a $\mathrm{PhD}$ student in 2006, in time to participate in showing much more sophisticated results using this scheme, in a paper which was featured on the (electronic) front cover of Optics Express [140]. Thomas then took this work and extended in angular range and, thus, in particle size resolution and to three dimensions [141] (Fig. 24).
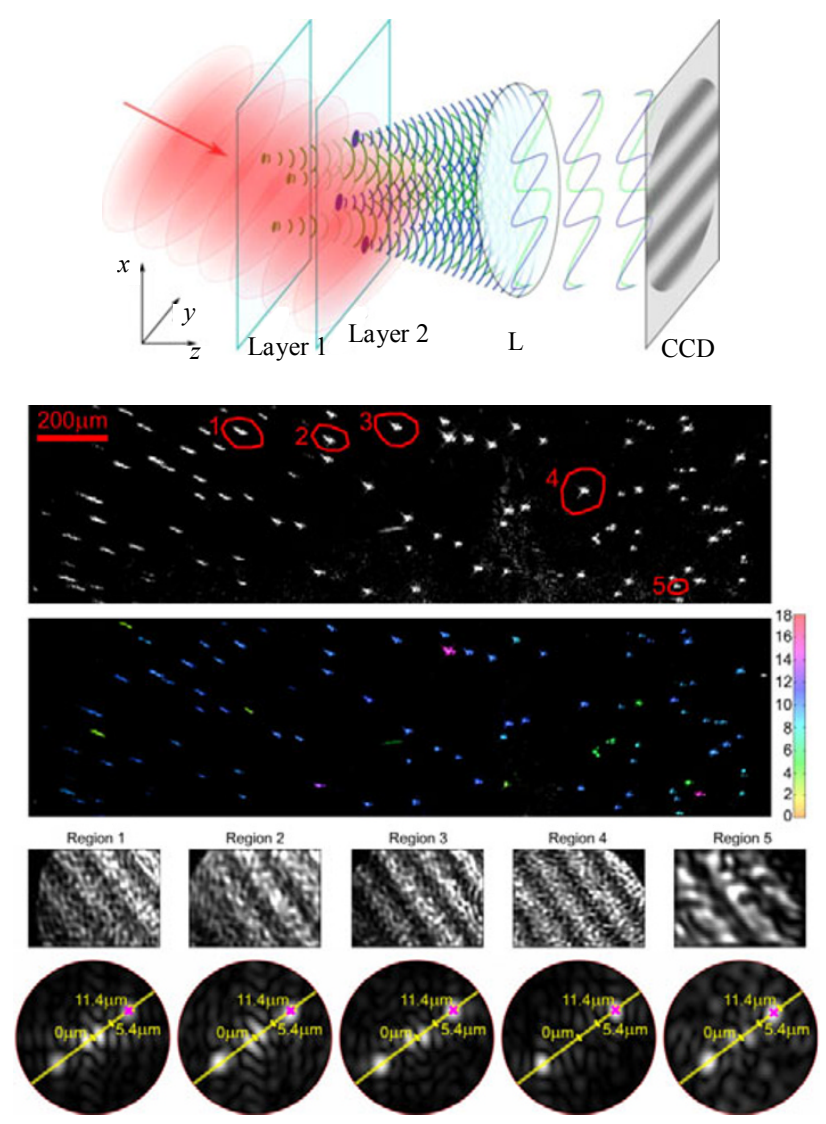

Fig. 24 3D concept of Fourier holographic angular scattering spectroscopy (above) and 2D demonstration of particle size mapping using it based on a single hologram (below) [140].

In the meantime, Sergey had another good idea Fourier holographic aperture synthesis. By illuminating a sample off-axis, we could tile spatial 
frequency space instead of image space, thus, building up a high-resolution large field of view image by gradual focusing rather than tiling small portions of image space. Tim contributed by developing the underlying theory and computational routines. We published a very nice paper in Physical

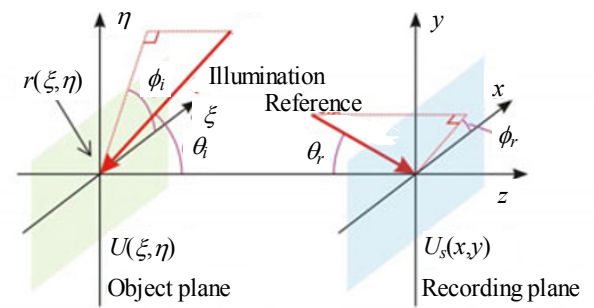

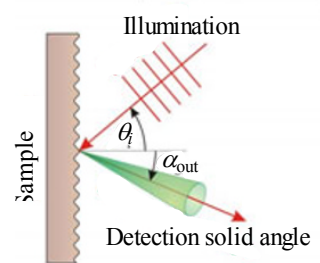

(b) (a)

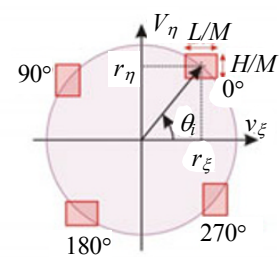

(c)
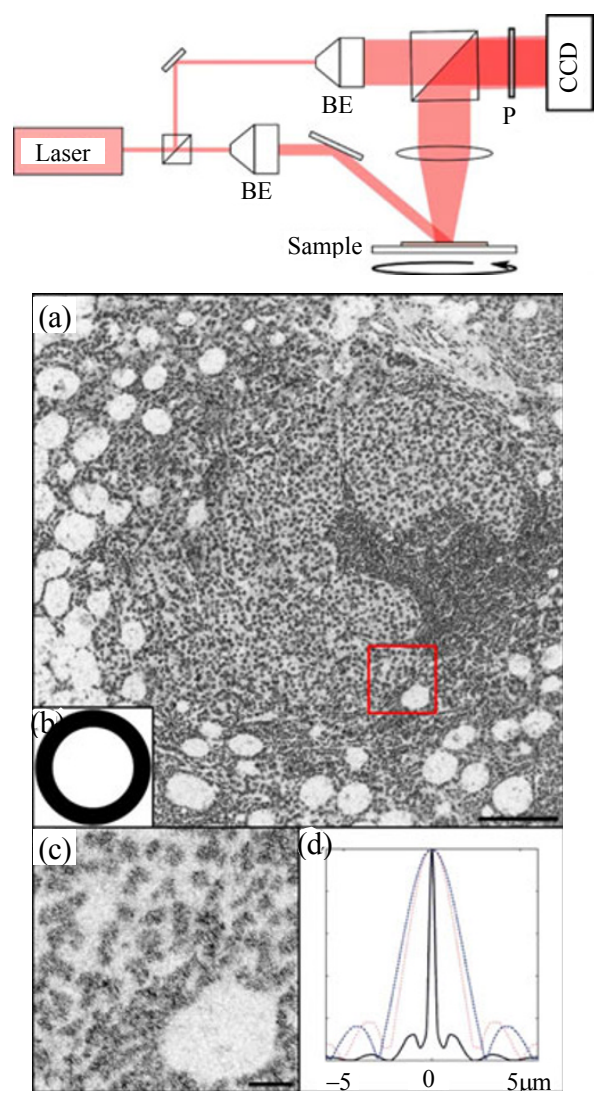

Fig. 25 Synthetic aperture Fourier holography concept (above), experimental realization (middle), and experimental result on thin tissue section (approx. $1 \mathrm{~mm} \times 1 \mathrm{~mm}$ ). After [142, 146]
Review Letters in 2006 [142]. Shortly thereafter, we received a "please explain" from the editor - a group had written claiming prior publication of an un-refereed SPIE paper more than a decade before. Indeed, the paper, which we had not seen, contained in essence the same idea, but with no experimental corroboration. We wrote a correction [143] - another lesson in research. In the meantime, both strands of this research were selected for optics in 2007 [144]. We continued to refine our scheme and published a substantial work in 2009 [145] and another in 2010 [146], in which Thomas showed just how well the scheme worked on tissue sections. He stitched together 180 holograms to achieve a numerical aperture of 0.93 , with $25 \times$ increase in spatial frequency over a single hologram, achieving sub-micron resolution over $9 \mathrm{~mm}^{2}$ at a working distance of $34 \mathrm{~mm}$, extraordinary performance (Fig. 25).

Sergey and I began a very promising line of research along a similar vein in 2008 [147] - we used wavelength encoding of spatial frequencies to map very small changes in extraordinarily large fields of view (Fig. 26).

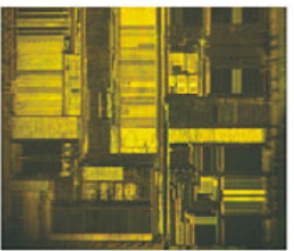

(a)

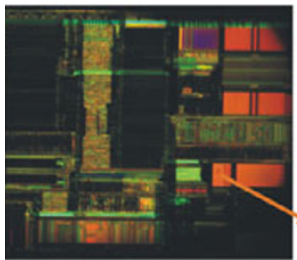

(c)

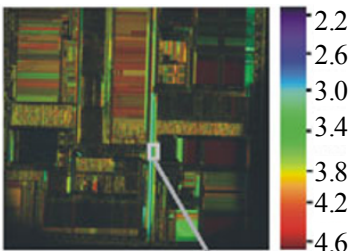

(b)

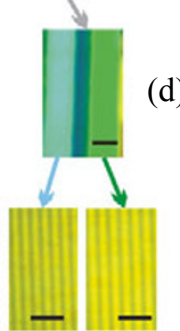

(f)
Fig. 26 Spectral encoding of spatial frequencies in a $15 \mathrm{~mm} \times 15 \mathrm{~mm}$ computer chip: (a) under white light, (b) spectral encoding, (c) spectral encoding at $90^{\circ}$, and (d)-(f) magnified portions [147]. 


\section{Conclusions}

My research career has taken me on a long journey of learning - from optical fiber technology to microwave photonics to optical communications to biomedical optics. An underlying theme has been a preoccupation with low coherence and its applications - enough said. Over my career to date, I have had the privilege to work with many extraordinary people who have continually amazed and inspired me. I hope I have done justice in some measure to their efforts in this paper. David Jackson taught me a great deal, although I didn't realize it at the time. He was a continual source of ideas and enthusiasm. He never stood in the way - quite the contrary - he made the space available to achieve, as is evident from the achievements of his lab. Much in the same way we cannot help but emulate our parents, those of us trained at Kent do the same, and for that we owe David Jackson a great debt of gratitude.

Open Access This article is distributed under the terms of the Creative Commons Attribution License which permits any use, distribution, and reproduction in any medium, provided the original author(s) and source are credited.

\section{References}

[1] T. G. Giallorenzi, J. A. Bucaro, A. Dandridge, G. H. Sigel, J. H. Cole, S. C. Rashleigh, and R. G. Priest, "Optical fiber sensor technology," IEEE Journal of Quantum Electronics, vol. 18, no. 4, pp. 626-665, 1982.

[2] D. D. Sampson and M. C. Elias, "Semiconductor laser stabilization using short external cavities," in Proc. 12th Australian Conference on Optical Fiber Technology, Sydney, Australia, December 6-9, pp. 151-154, 1987.

[3] D. T. Cassidy, "Trace gas-detection using 1.3- $\mu \mathrm{m}$ InGaAsP diode-laser transmitter modules," Applied Optics, vol. 27, no. 3, pp. 610-614, 1988.

[4] G. Stewart, W. Johnstone, J. R. P. Bain, K. Ruxton, and K. Duffin, "Recovery of absolute gas absorption line shapes using tunable diode laser spectroscopy with wavelength modulation - Part I: theoretical analysis," Journal of Lightwave Technology, vol. 29, no. 6, pp. 811-821, 2011.

[5] J. H. Van Vleck and D. Middleton, "Spectrum of clipped noise," in Proceedings of the Institute of Electrical and Electronics Engineers, vol. 54, pp. 2-19, 1966.

[6] R. H. Brown and R. Q. Twiss, "Correlation between photons in 2 coherent beams of light," Nature, vol. 177, no. 4497, pp. 27-29, 1956.

[7] H. Z. Cummins and E. R. Pike, Eds., Photon Correlation and Light Beating Spectroscopy. Nato Advanced Study Institute, New York: Plenum, 1973.

[8] A. R. Thompson, J. M. Moran, and G. W. Swenson, Interferometry and Synthesis in Radio Astronomy. New York: Wiley, 1986.

[9] D. A. Jackson and J. D. C. Jones, "Proposed topologies for a fiber-optic-based 1-GHz clipped digital correlator," Optics Letters, vol. 11, no. 12, pp. 824- 826, 1986.

[10] K. P. Jackson and H. J. Shaw, "Fiber-optic delay line processors," in Optical Signal Processing, J. L. Horner Ed., New York: Academic Press, 1987.

[11] B. Moslehi, J. W. Goodman, M. Tur, and H. J. Shaw, "Fiber-optic lattice signal-processing," in Proceedings of the IEEE, vol. 72, pp. 909-930, 1984.

[12] D. D. Sampson and D. A. Jackson, "High-speed optical pulse generation using single-mode optical fiber networks," Review of Scientific Instruments, vol. 62, no. 1, pp. 36-41, 1991.

[13] J. L. Hullett and T. V. Muoi, "A feedback receive amplifier for optical transmission-systems," IEEE Transactions on Communications, vol. 24, no. 10, pp. 1180-1185, 1976.

[14] D. D. Sampson and D. A. Jackson, "Experimental realization of a fiber-optic-based multichannel digital correlator," Optics Letters, vol. 16, no. 23, pp. 1899-1901, 1991.

[15] D. D. Sampson, W. T. Dove, and D. A. Jackson, "High-bandwidth, optical-fiber delay-line multichannel digital correlator," Applied Optics, vol. 32, no. 21, pp. 3905-3916, 1993.

[16] D. D. Sampson and D. A. Jackson, "Coherent optical fiber communications system using all-optical correlation processing," Optics Letters, vol. 15, no. 10, pp. 585-587, 1990.

[17] M. E. Marhic and Y. L. Chang, "Pulse coding and coherent decoding in fiber-optic ladder networks," 
Electronics Letters, vol. 25, no. 22, pp. 1535-1536, 1989.

[18] Y. L. Chang and M. E. Marhic, "Fiberoptic ladder networks for inverse decoding coherent CDMA," Journal of Lightwave Technology, vol. 10, no. 12, pp. 1952-1962, 1992.

[19] C. Delisle and P. Cielo, "Application of spectrum modulation to data transfer," Canadian Journal of Physics, vol. 53, no. 11, pp. 1047-1053, 1975.

[20] J. P. Goedgebuer, H. Porte, and A. Hamel, "Electrooptic modulation of multilongitudinal mode laser-diodes - demonstration at $850 \mathrm{~nm}$ with simultaneous data-transmission by coherence multiplexing," IEEE Journal of Quantum Electronics, vol. 23, no. 7, pp. 1135-1144, 1987.

[21] S. A. Al-Chalabi, B. Culshaw, and D. E. N. Davies, "Partially coherent sources in interferometric sensors," in Proc. 1st International Conference on Optical Fiber Sensors (IEE), London, United Kingdom, April 26-28, pp. 132-135, 1983.

[22] J. L. Brooks, R. H. Wentworth, R. C. Youngquist, M. Tur, B. Y. Kim, and H. J. Shaw, "Coherence multiplexing of fiber-optic interferometric sensors," Journal of Lightwave Technology, vol. 3, no.5, pp. 1062-1072, 1985.

[23] J. P. Goedgebuer and A. Hamel, "Coherence multiplexing using a parallel array of electrooptic modulators and multimode semiconductor-lasers," IEEE Journal of Quantum Electronics, vol. 23, no. 12, pp. 2224-2237, 1987.

[24] D. D. Sampson, R. A. Griffin, and D. A. Jackson, "Photonic CDMA by coherent matched filtering using time-addressed coding in optical ladder networks," Journal of Lightwave Technology, vol. 12, no. 11, pp. 2001-2010, 1994.

[25] D. D. Sampson, M. Calleja, and R. A. Griffin, "Crosstalk performance of coherent time-addressed photonic CDMA networks," IEEE Transactions on Communications, vol. 46, no. 3, pp. 338-348, 1998.

[26] R. A. Griffin, D. D. Sampson, and D. A. Jackson, "Demonstration of data-transmission using coherent correlation to reconstruct a coded pulse sequence," IEEE Photonics Technology Letters, vol. 4, no. 5, pp. 513-515, 1992.

[27] R. A. Griffin, D. D. Sampson, and D. A. Jackson, "Optical-phase coding for code-division multiple access networks," IEEE Photonics Technology Letters, vol. 4, no. 12, pp. 1401-1404, 1992.

[28] J. A. Salehi, A. M. Weiner, and J. P. Heritage, "Coherent ultrashort light-pulse code-division multiple access communication systems," Journal of Lightwave Technology, vol. 8, no. 3, pp. 478-491, 1990.

[29] A. M. Weiner, J. P. Heritage, and E. M. Kirschner, "High-resolution femtosecond pulse shaping," Journal of the Optical Society of America B-Optical Physics, vol. 5, no. 8, pp. 1563-1572, 1988.

[30] R. A. Griffin, D. D. Sampson, and D. A. Jackson, "Modification of optical coherence using spectral phase coding for use in photonic code-division multiple-access systems," Electronics Letters, vol. 29, no. 25, pp. 2214-2216, 1993.

[31] R. A. Griffin, D. D. Sampson, and D. A. Jackson, "Coherence coding for photonic code-division multiple-access networks," Journal of Lightwave Technology, vol. 13, no. 9, pp. 1826-1837, 1995.

[32] J. W. Goodman, Statistical Optics. New York: John Wiley \& Sons, 2000.

[33] P. Healey, "Dimensioning an optical-fiber spread-spectrum multiple-access communication system," Optics Letters, vol. 12, no. 6, pp. 425-427, 1987.

[34] K. W. Chu and F. M. Dickey, "Optical coherence multiplexing for interprocessor communications," Optical Engineering, vol. 30, no. 3, pp. 337-344, 1991.

[35] R. H. Wentworth, "Theoretical noise performance of coherence-multiplexed interferometric sensors," Journal of Lightwave Technology, vol. 7, no. 6, pp. 941-956, 1989.

[36] P. R. Prucnal and M. A. Santoro, "Spread spectrum fiberoptic local area network using optical-processing," Journal of Lightwave Technology, vol. 4, no. 5, pp. 547-554, 1986

[37] D. Brady and S. Verdú, "A semiclassical analysis of optical code division multiple access," IEEE Transactions on Communications, vol. 39, no. 1, pp. 85-93, 1991.

[38] D. D. Sampson, G. J. Pendock, and R. A. Griffin, "Photonic code-division multiple-access communications," Fiber and Integrated Optics, vol. 16, no. 2, pp. 129-157, 1997.

[39] G. J. Pendock, M. J. L. Cahill, and D. D. Sampson, "Multigigabit-per-second demonstration of photonic code-division multiplexing," Electronics Letters, vol. 31, no. 10, pp. 819-820, 1995.

[40] G. J. Pendock and D. D. Sampson, "Increasing the transmission capacity of coherence multiplexed communication systems by using differential detection," IEEE Photonics Technology Letters, vol. 
7, no. 12, pp. 1504-1506, 1995.

[41] G. J. Pendock and D. D. Sampson, "Noise in coherence-multiplexed optical fiber systems," Applied Optics, vol. 36, no. 36, pp. 9536-9540, 1997.

[42] G. J. Pendock and D. D. Sampson, "Capacity of coherence-multiplexed cdma networks," Optics Communications, vol. 143, no. 1-3, pp. 109-117, 1997.

[43] M. H. Reeve, A. R. Hunwicks, W. Zhao, S. G. Methley, L. Bickers, and S. Hornung, "LED spectral slicing for single-mode local loop applications," Electronics Letters, vol. 24, no. 7, pp. 389-390, 1988.

[44] D. D. Sampson and W. T. Holloway, "100-mW spectrally-uniform broad-band ASE source for spectrum-sliced WDM systems," Electronics Letters, vol. 30, no. 19, pp. 1611-1612, 1994.

[45] M. Tachibana, R. I. Laming, P. R. Morkel, and D. N. Payne, "Erbium-doped fiber amplifier with flattened gain spectrum," IEEE Photonics Technology Letters, vol. 3, no. 2, pp. 118-120, 1991.

[46] D. D. Sampson and W. T. Holloway, "Transmission of $622 \mathrm{Mbit} / \mathrm{s}$ spectrum-sliced WDM channel over $60 \mathrm{~km}$ of nondispersion-shifted fiber at $1550 \mathrm{~nm}$," Electronics Letters, vol. 30, no. 21, pp. 1767-1768, 1994.

[47] A. J. Keating, W. T. Holloway, and D. D. Sampson, "Feedforward noise reduction of incoherent light for spectrum-sliced transmission at $2.5 \mathrm{~Gb} / \mathrm{s}$," IEEE Photonics Technology Letters, vol. 7, no. 12, pp. 1513-1515, 1995.

[48] A. J. Keating and D. D. Sampson, "Reduction of excess intensity noise in spectrum-sliced incoherent light for WDM applications," Journal of Lightwave Technology, vol. 15, no. 1, pp. 53-61, 1997.

[49] W. T. Holloway, A. J. Keating, and D. D. Sampson, "Multiwavelength source for spectrum-sliced WDM access networks and LAN's," IEEE Photonics Technology Letters, vol. 9, no. 7, pp. 1014-1016, 1997.

[50] R. D. T. Lauder, J. M. Badcock, W. T. Holloway, and D. D. Sampson, "WDM ring network employing a shared multiwavelength incoherent source," IEEE Photonics Technology Letters, vol. 10, no. 2, pp. 294-296, 1998.

[51] G. J. Pendock and D. D. Sampson, "Transmission performance of high bit rate spectrum-sliced WDM systems," Journal of Lightwave Technology, vol. 14, no. 10, pp. 2141-2148, 1996.
[52] S. D. Personick, "Baseband linearity and equalization in fiber optic digital communication systems," Bell System Technical Journal, vol. 52, no. 7, pp. 1175-1194, 1973.

[53] D. Marcuse, "Calculation of bit-error probability for a lightwave system with optical amplifiers and postdetection Gaussian-noise," Journal of Lightwave Technology, vol. 9, no. 4, pp. 505-513, 1991.

[54] G. J. Pendock and D. D. Sampson, "Signal-to-noise ratio of modulated sources of ase transmitted over dispersive fiber," IEEE Photonics Technology Letters, vol. 9, no. 7, pp. 1002-1004, 1997.

[55] R. A. Griffin, D. A. Jackson, and D. D. Sampson, "Coherence and noise properties of gain-switched Fabry-Perot semiconductor lasers," IEEE Journal of Selected Topics in Quantum Electronics, vol. 1, no. 2, pp. 569-576, 1995.

[56] M. J. L. Cahill, G. J. Pendock, and D. D. Sampson, "Low error rate return-to-zero direct modulation of gain-switched lasers," Optical and Quantum Electronics, vol. 28, no. 9, pp. 1181-1185, 1996.

[57] D. S. Seo, H. F. Liu, D. Y. Kim, and D. D. Sampson, "Injection power and wavelength dependence of an external-seeded gain-switched Fabry-Perot laser," Applied Physics Letters, vol. 67, no. 11, pp. 1503-1505, 1995.

[58] D. Huang, E. A. Swanson, C. P. Lin, J. S. Schuman, W. G. Stinson, W. Chang, M. R. Hee, T. Flotte, K. Gregory, C. A. Puliafito, and J. G. Fujimoto, "Optical coherence tomography," Science, vol. 254, no. 5035, pp. 1178-1181, 1991.

[59] D. D. Sampson and T. R. Hillman, "Optical coherence tomography," in Lasers and Current Optical Techniques in Biology, vol. 4, G. Palumbo and R. Pratesi, Eds. Cambridge, UK: Royal Society of Chemistry, 2004, pp. 481-571.

[60] T. R. Hillman and D. D. Sampson, "The effect of water dispersion and absorption on axial resolution in ultrahigh-resolution optical coherence tomography," Optics Express, vol. 13, no. 6, pp. 1860-1874, 2005.

[61] E. D. J. Smith, A. V. Zvyagin, and D. D. Sampson, "Real-time dispersion compensation in scanning interferometry," Optics Letters, vol. 27, no. 22, pp. 1998-2000, 2002.

[62] J. K. Ranka, R. S. Windeler, and A. J. Stentz, "Visible continuum generation in air-silica microstructure optical fibers with anomalous dispersion at $800 \mathrm{~nm}$," Optics Letters, vol. 25, no. 1, pp. 25-27, 2000. 
[63] E. D. J. Smith, S. C. Moore, N. Wada, W. Chujo, and D. D. Sampson, "Spectral domain interferometry for ocdr using non-gaussian broad-band sources," IEEE Photonics Technology Letters, vol. 13, no. 1, pp. 64-66, 2001.

[64] E. D. J. Smith, N. Wada, W. Chujo, and D. D. Sampson, "High resolution OCDR using $1.55 \mu \mathrm{m}$ supercontinuum source and quadrature spectral detection," Electronics Letters, vol. 37, no. 21, pp. 1305-1307, 2001.

[65] R. Tripathi, N. Nassif, J. S. Nelson, B. H. Park, and J. F. de Boer, "Spectral shaping for non-Gaussian source spectra in optical coherence tomography," Optics Letters, vol. 27, no. 6, pp. 406-408, 2002.

[66] B. Povazay, K. Bizheva, A. Unterhuber, B. Hermann, H. Sattmann, A. F. Fercher, W. Drexler, A. Apolonski, W. J. Wadsworth, J. C. Knight, P. S. J. Russell, M. Vetterlein, and E. Scherzer, "Submicrometer axial resolution optical coherence tomography," Optics Letters, vol. 27, no. 20, pp. 1800-1802, 2002.

[67] D. D. Sampson, N. Wada, K. Kitayama, and W. Chujo, "Demonstration of reconfigurable all-optical code conversion for photonic code-division multiplexing and networking," Electronics Letters, vol. 36, no. 5, pp. 445-447, 2000.

[68] J. W. Goodman, Speckle Phenomena in Optics: Theory and Applications. Englewood: Roberts \& Company, 2007.

[69] J. C. Dainty, Laser Speckle and Related Phenomena, Second ed. Heidelberg: Springer, 1984.

[70] J. M. Schmitt, S. H. Xiang, and K. M. Yung, "Speckle in optical coherence tomography," Journal of Biomedical Optics, vol. 4, no. 1, pp. 95-105, 1999.

[71] T. R. Hillman, S. G. Adie, V. Seemann, J. J. Armstrong, S. L. Jacques, and D. D. Sampson, "Correlation of static speckle with sample properties in optical coherence tomography," Optics Letters, vol. 31, no. 2, pp. 190-192, 2006.

[72] B. F. Kennedy, T. R. Hillman, A. Curatolo, and D. D. Sampson, "Speckle reduction in optical coherence tomography by strain compounding," Optics Letters, vol. 35, no. 14, pp. 2445-2447, 2010.

[73] B. F. Kennedy, A. Curatolo, T. R. Hillman, C. M. Saunders, and D. D. Sampson, "Speckle reduction in optical coherence tomography images using tissue viscoelasticity," Journal of Biomedical Optics, vol. 16, no. 2, 2011.

[74] D. D. Sampson, “Optical bioimaging 2010: Seeing more, deeper, faster," IEEE Photonics Journal, vol. 3, no. 2, pp. 278-283, 2011.

[75] J. C. Clements, A. V. Zvyagin, K. K. M. B. D. Silva, T. Wanner, D. D. Sampson, and W. A. Cowling, "Optical coherence tomography as a novel tool for non-destructive measurement of the hull thickness of lupin seeds," Plant Breeding, vol. 123, no. 3, pp. 266-270, 2004.

[76] S. G. Adie, T. R. Hillman, and D. D. Sampson, "Detection of multiple scattering in optical coherence tomography using the spatial distribution of stokes vectors," Optics Express, vol. 15, no. 26, pp. 18033-18049, 2007.

[77] T. R. Hillman, A. Curatolo, B. F. Kennedy, and D. D. Sampson, "Detection of multiple scattering in optical coherence tomography by speckle correlation of angle-dependent B-scans," Optics Letters, vol. 35, no. 12, pp. 1998-2000, 2010.

[78] D. D. Sampson and D. A. Jackson, "Spread-spectrum optical fiber network based on pulsed coherent correlation," Electronics Letters, vol. 26, no. 19, pp. 1550-1552, 1990.

[79] K. F. Kwong, D. Yankelevich, K. C. Chu, J. P. Heritage, and A. Dienes, " $400-\mathrm{Hz}$ mechanical scanning optical delay-line," Optics Letters, vol. 18, no. 7, pp. 558-560, 1993

[80] R. N. Thurston, J. P. Heritage, A. M. Weiner, and W. J. Tomlinson, "Analysis of picosecond pulse shape synthesis by spectral masking in a grating pulse compressor," IEEE Journal of Quantum Electronics, vol. 22, no. 5, pp. 682-696, 1986.

[81] G. J. Tearney, B. E. Bouma, and J. G. Fujimoto, "High-speed phase- and group-delay scanning with a grating-based phase control delay line," Optics Letters, vol. 22, no. 23, pp. 1811-1813, 1997.

[82] A. M. Rollins, M. D. Kulkarni, S. Yazdanfar, R. Ung-arunyawee, and J. A. Izatt, "In vivo video rate optical coherence tomography," Optics Express, vol. 3, no. 6, pp. 219-228, 1998.

[83] K. K. M. B. D. Silva, A. V. Zvyagin, and D. D. Sampson, "Extended range, rapid scanning optical delay line for biomedical interferometric imaging," Electronics Letters, vol. 35, no. 17, pp. 1404-1406, 1999.

[84] A. V. Zvyagin and D. D. Sampson, "Achromatic optical phase shifter-modulator," Optics Letters, vol. 26, no. 4, pp. 187-189, 2001.

[85] A. V. Zvyagin, E. D. J. Smith, and D. D. Sampson, "Delay and dispersion characteristics of a frequency-domain optical delay line for scanning 
interferometry," Journal of the Optical Society of America A-Optics Image Science and Vision, vol. 20, no. 2, pp. 333-341, 2003.

[86] R. Barer, "Refractometry and interferometry of living cells," Journal of the Optical Society of America, vol. 47, no. 6, pp. 545-556, 1957.

[87] G. J. Tearney, M. E. Brezinski, J. F. Southern, B. E. Bouma, M. R. Hee, and J. G. Fujimoto, "Determination of the refractive-index of highly scattering human tissue by optical coherence tomography," Optics Letters, vol. 20, no. 21, pp. 2258-2260, 1995.

[88] S. A. Alexandrov, A. V. Zvyagin, K. K. M. B. D. Silva, and D. D. Sampson, "Bifocal-optical coherenc refractometry of turbid media," Optics Letters, vol. 28, no. 2, pp. 117-119, 2003.

[89] A. V. Zvyagin, K. K. M. B. D. Silva, S. A. Alexandrov, T. R. Hillman, J. J. Armstrong, T. Tsuzuki, and D. D. Sampson, "Refractive index tomography of turbid media by bifocal optical coherence refractometry," Optics Express, vol. 11, no. 25, pp. 3503-3517, 2003.

[90] A. M. Zysk, S. G. Adie, J. J. Armstrong, M. S. Leigh, A. Paduch, D. D. Sampson, F. T. Nguyen, and S. A. Boppart, "Needle-based refractive index measurement using low-coherence interferometry," Optics Letters, vol. 32, no. 4, pp. 385-387, 2007.

[91] A. M. Zysk, D. L. Marks, D. Y. Liu, and S. A. Boppart, "Needle-based reflection refractometry of scattering samples using coherence-gated detection," Optics Express, vol. 15, no. 8, pp. 4787-4794, 2007.

[92] R. A. McLaughlin, L. Scolaro, P. Robbins, C. Saunders, S. L. Jacques, and D. D. Sampson, "Parametric imaging of cancer with optical coherence tomography," Journal of Biomedical Optics, vol. 15, no. 4, pp. 046029, 2010.

[93] S. G. Adie, B. F. Kennedy, J. J. Armstrong, S. A. Alexandrov, and D. D. Sampson, "Audio frequency in vivo optical coherence elastography," Physics in Medicine and Biology, vol. 54, no. 10, pp. 3129-3139, 2009.

[94] B. F. Kennedy, T. R. Hillman, R. A. McLaughlin, B. C. Quirk, and D. D. Sampson, "In vivo dynamic optical coherence elastography using a ring actuator," Optics Express, vol. 17, no. 24, pp. 21762-21772, 2009.

[95] S. G. Adie, X. Liang, B. F. Kennedy, R. John, D. D. Sampson, and S. A. Boppart, "Spectroscopic optical coherence elastography," Optics Express, vol. 18, no.
25, pp. 25519-25534, 2010.

[96] B. F. Kennedy, X. Liang, S. G. Adie, D. K. Gerstmann, B. C. Quirk, S. A. Boppart, and D. D. Sampson, "In vivo three-dimensional optical coherence elastography," Optics Express, vol. 19, no. 7, pp. 6623-6634, 2011.

[97] J. F. Greenleaf, M. Fatemi, and M. Insana, "Selected methods for imaging elastic properties of biological tissues," Annual Review of Biomedical Engineering, vol. 5, pp. 57-78, 2003.

[98] R. Muthupillai, D. J. Lomas, P. J. Rossman, J. F. Greenleaf, A. Manduca, and R. L. Ehman, "Magnetic-resonance elastography by direct visualization of propagating acoustic strain waves," Science, vol. 269, no. 5232, pp. 1854-1857, 1995.

[99] J. M. Schmitt, "OCT elastography: imaging microscopic deformation and strain of tissue," Optics Express, vol. 3, no. 6, pp. 199-211, 1998.

[100] B. F. Kennedy, S. Loitsch, R. A. McLaughlin, L. Scolaro, P. Rigby, and D. D. Sampson, "Fibrin phantom for use in optical coherence tomography," Journal of Biomedical Optics, vol. 15, no. 3, pp. 030507, 2010.

[101] A. Curatolo, B. F. Kennedy, and D. D. Sampson, "Structured three-dimensional optical phantoms for optical coherence tomography," Optics Express, vol. 19, 2011 (in press).

[102] X. D. Li, C. Chudoba, T. Ko, C. Pitris, and J. G. Fujimoto, "Imaging needle for optical coherence tomography," Optics Letters, vol. 25, no. 20, pp. 1520-1522, 2000.

[103] J. C. Jung, A. D. Mehta, E. Aksay, R. Stepnoski, and M. J. Schnitzer, "In vivo mammalian brain imaging using one- and two-photon fluorescence microendoscopy," Journal of Neurophysiology, vol. 92, no. 5, pp. 3121-3133, 2004.

[104] B. C. Quirk, R. A. McLaughlin, A. Curatolo, R. W. Kirk, P. B. Noble, and D. D. Sampson, "In situ imaging of lung alveoli with an OCT needle probe," Journal of Biomedical Optics, vol. 16, no. 3, pp. 036009, 2011.

[105] R. A. McLaughlin, L. Scolaro, P. Robbins, S. Hamza, C. Saunders, and D. D. Sampson, "Imaging of human lymph nodes using optical coherence tomography: potential for staging cancer," Cancer Research, vol. 70, no. 7, pp. 2579-2584, 2010.

[106] W. Drexler and J. G. Fujimoto (editors), Optical Coherence Tomography: Technology and Applications. Heidelberg: Springer, 2008. 
[107] S. A. Boppart, W. Luo, D. L. Marks, and K. W. Singletary, "Optical coherence tomography: feasibility for basic research and image-guided surgery of breast cancer," Breast Cancer Research and Treatment, vol. 84, no. 2, pp. 85-97, 2004.

[108]C. Zhou, D. W. Cohen, Y. H. Wang, H. C. Lee, A. E. Mondelblatt, T. H. Tsai, A. D. Aguirre, J. G. Fujimoto, and J. L. Connolly, "Integrated optical coherence tomography and microscopy for ex vivo multiscale evaluation of human breast tissues," Cancer Research, vol. 70, no. 24, pp. 10071-10079, 2010.

[109] M. J. Cobb, J. H. Hwang, M. P. Upton, Y. C. Chen, B. K. Oelschlager, D. E. Wood, M. B. Kimmey, and X. D. Li, "Imaging of subsquamous Barrett's epithelium with ultrahigh-resolution optical coherence tomography: a histologic correlation study," Gastrointestinal Endoscopy, vol. 71, no. 2, pp. 223-230, 2010.

[110] J. J. Armstrong, M. S. Leigh, I. D. Walton, A. V. Zvyagin, S. A. Alexandrov, S. Schwer, D. D. Sampson, D. R. Hillman, and P. R. Eastwood, "In vivo size and shape measurement of the human upper airway using endoscopic long-range optical coherence tomography," Optics Express, vol. 11, no. 15, pp. 1817-1826, 2003.

[111] J. J. Armstrong, M. S. Leigh, D. D. Sampson, J. H. Walsh, D. R. Hillman, and P. R. Eastwood, "Quantitative upper airway imaging with anatomic optical coherence tomography," American Journal of Respiratory and Critical Care Medicine, vol. 173, no. 2, pp. 226-233, 2006.

[112] M. S. Leigh, J. J. Armstrong, A. Paduch, J. H. Walsh, D. R. Hillman, P. R. Eastwood, and D. D. Sampson, "Anatomical optical coherence tomography for long-term, portable, quantitative endoscopy," IEEE Transactions on Biomedical Engineering, vol. 55, no. 4, pp. 1438-1446, 2008.

[113] R. A. McLaughlin, J. P. Williamson, M. J. Phillips, J. J. Armstrong, S. Becker, D. R. Hillman, P. R. Eastwood, and D. D. Sampson, "Applying anatomical optical coherence tomography to quantitative 3D imaging of the lower airway," Optics Express, vol. 16, no. 22, pp. 17521-17529, 2008.

[114] J. H. Walsh, M. S. Leigh, A. Paduch, K. J. Maddison, J. J. Armstrong, D. D. Sampson, D. R. Hillman, and P. R. Eastwood, "Effect of body posture on pharyngeal shape and size in adults with and without obstructive sleep apnea," Sleep, vol. 31, no. 11, pp. 1543-1549, 2008.

[115] J. H. Walsh, M. S. Leigh, A. Paduch, K. J. Maddison, D. L. Philippe, J. J. Armstrong, D. D. Sampson, D. R. Hillman, and P. R. Eastwood, "Evaluation of pharyngeal shape and size using anatomical optical coherence tomography in individuals with and without obstructive sleep apnoea," Journal of Sleep Research, vol. 17, no. 2, pp. $230-238,2008$.

[116] R. A. McLaughlin, J. J. Armstrong, S. Becker, J. H. Walsh, A. Jain, D. R. Hillman, P. R. Eastwood, and D. D. Sampson, "Respiratory gating of anatomical optical coherence tomography images of the human airway," Optics Express, vol. 17, no. 8, pp. 6568-6577, 2009.

[117] J. P. Williamson, R. A. McLaughlin, M. J. Phillips, J. J. Armstrong, S. Becker, J. H. Walsh, D. D. Sampson, D. R. Hillman, and P. R. Eastwood, "Using optical coherence tomography to improve diagnostic and therapeutic bronchoscopy," Chest, vol. 136, no. 1, pp. 272-276, 2009.

[118] P. B. Noble, R. A. McLaughlin, A. R. West, S. Becker, J. J. Armstrong, P. K. McFawn, P. R. Eastwood, D. R. Hillman, D. D. Sampson, and H. W. Mitchell, "Distribution of airway narrowing responses across generations and at branching points, assessed in vitro by anatomical optical coherence tomography," Respiratory Research, vol. 11, no. 1, doi:10.1186/1465-9921-11-9 (12 pages), 2010.

[119] P. B. Noble, A. R. West, R. A. McLaughlin, J. J. Armstrong, S. Becker, P. K. McFawn, J. P. Williamson, P. R. Eastwood, D. R. Hillman, D. D. Sampson, and H. W. Mitchell, "Airway narrowing assessed by anatomical optical coherence tomography in vitro: dynamic airway wall morphology and function," Journal of Applied Physiology, vol. 108, no. 2, pp. 401-411, 2010.

[120] J. P. Williamson, J. J. Armstrong, R. A. McLaughlin, P. B. Noble, A. R. West, S. Becker, A. Curatolo, W. J. Noffsinger, H. W. Mitchell, M. J. Phillips, D. D. Sampson, D. R. Hillman, and P. R. Eastwood, "Measuring airway dimensions during bronchoscopy using anatomical optical coherence tomography," European Respiratory Journal, vol. 35, no. 1, pp. 34-41, 2010.

[121] J. P. Williamson, R. A. McLaughlin, W. J. Noffsingerl, A. L. James, V. A. Baker, A. Curatolo, J. J. Armstrong, A. Regli, K. L. Shepherd, G. B. Marks, D. D. Sampson, D. R. Hillman, and P. R. 
Eastwood, "Elastic properties of the central airways in obstructive lung diseases measured using anatomical optical coherence tomography," American Journal of Respiratory and Critical Care Medicine, vol. 183, no. 5, pp. 612-619, 2011.

[122] J. J. Armstrong and D. D. Sampson, "Distance ranging to biological tissue using fiber-optic Fabry-Perot, short tuning range FMCW interferometry," in Proc. SPIE (OFS-14), vol. 4185 (A. G. Mignani, H. C. Lefevre, Eds.), pp. 366-369, 2000.

[123] B. Lau, R. A. McLaughlin, A. Curatolo, R. W. Kirk, D. K. Gerstmann, and D. D. Sampson, "Imaging true $3 \mathrm{~d}$ endoscopic anatomy by incorporating magnetic tracking with optical coherence tomography: proof-of-principle for airways," Optics Express, vol. 18, no. 26, pp. 27173-27180, 2010.

[124] A. D. Lucey, A. J. C. King, G. A. Tetlow, J. Wang, J. J. Armstrong, M. S. Leigh, A. Paduch, J. H. Walsh, D. D. Sampson, P. R. Eastwood, and D. R. Hillman, "Measurement, reconstruction, and flow-field computation of the human pharynx with application to sleep apnea," IEEE Transactions on Biomedical Engineering, vol. 57, no. 10, pp. 2535-2548, 2010.

[125] J. P. Williamson, R. A. McLaughlin, M. J. Phillips, A. Curatolo, J. J. Armstrong, K. J. Maddison, R. E. Sheehan, D. D. Sampson, D. R. Hillman, and P. R. Eastwood, "Feasibility of applying real-time optical imaging during bronchoscopic interventions for central airway obstruction," Journal of Bronchology and Interventional Pulmonology, vol. 17, no. 4, pp. 307-316, 2010.

[126] P. D. Pare, "Central airway compliance in asthma up or down? Good or bad?," American Journal of Respiratory and Critical Care Medicine, vol. 183, no. 5, pp. 563-564, 2011.

[127]O. Vargas, E. K. Chan, J. K. Barton, H. G. Rylander, and A. J. Welch, "Use of an agent to reduce scattering in skin," Lasers in Surgery and Medicine, vol. 24, no. 2, pp. 133-141, 1999.

[128] G. Vargas, K. F. Chan, S. L. Thomsen, and A. J. Welch, "Use of osmotically active agents to alter optical properties of tissue: effects on the detected fluorescence signal measured through skin," Lasers in Surgery and Medicine, vol. 29, no. 3, pp. 213-220, 2001.

[129] R. Cicchi, F. S. Pavone, D. Massi, and D. D. Sampson, "Contrast and depth enhancement in two-photon microscopy of human skin ex vivo by use of optical clearing agents," Optics Express, vol. 13, no. 7, pp. 2337-2344, 2005.

[130] V. V. Tuchin, Optical Clearing of Tissues and Blood. Bellingham, Wash.: SPIE Press, 2006.

[131] J. M. Schmitt and G. Kumar, "Turbulent nature of refractive-index variations in biological tissue," Optics Letters, vol. 21, no. 16, pp. 1310-1312, 1996.

[132] J. M. Schmitt and A. Knüttel, "Model of optical coherence tomography of heterogeneous tissue," Journal of the Optical Society of America A-Optics Image Science and Vision, vol. 14, no. 6, pp. 1231-1242, 1997.

[133] J. M. Schmitt and G. Kumar, "Optical scattering properties of soft tissue: A discrete particle model," Applied Optics, vol. 37, no. 13, pp. 2788-2797, 1998.

[134] D. H. P. Schneiderheinze, T. R. Hillman, and D. D. Sampson, "Modified discrete particle model of optical scattering in skin tissue accounting for multiparticle scattering," Optics Express, vol. 15, no. 23, pp. 15002-15010, 2007.

[135] C. A. Morton and R. M. MacKie, "Clinical accuracy of the diagnosis of cutaneous malignant melanoma," British Journal of Dermatology, vol. 138, no. 2, pp. 283-287, 1998.

[136] C. M. Grin, A. W. Kopf, B. Welkovich, R. S. Bart, and M. J. Levenstein, "Accuracy in the clinical diagnosis of malignant melanoma," Archives of Dermatology, vol. 126, no. 6, pp. 763-766, 1990.

[137] B. W. Murphy, R. J. Webster, B. A. Turlach, C. J. Quirk, C. D. Clay, P. J. Heenan, and D. D. Sampson, "Toward the discrimination of early melanoma from common and dysplastic nevus using fiber optic diffuse reflectance spectroscopy," Journal of Biomedical Optics, vol. 10, no. 6, pp. 064020, 2005.

[138] N. N. Boustany, S. C. Kuo, and N. V. Thakor, "Optical scatter imaging: Subcellular morphometry in situ with Fourier filtering," Optics Letters, vol. 26, no. 14, pp. 1063-1065, 2001.

[139] S. A. Alexandrov, T. R. Hillman, and D. D. Sampson, "Spatially resolved Fourier holographic light scattering angular spectroscopy," Optics Letters, vol. 30, no. 24, pp. 3305-3307, 2005.

[140] T. R. Hillman, S. A. Alexandrov, T. Gutzler, and D. D. Sampson, "Microscopic particle discrimination using spatially-resolved fourier-holographic light scattering angular 
spectroscopy," Optics Express, vol. 14, pp. 11088-11102, 2006.

[141] T. Gutzler, T. R. Hillman, S. A. Alexandrov, and D. D. Sampson, "Three-dimensional depth-resolved and extended-resolution micro-particle characterization by holographic light scattering spectroscopy," Optics Express, vol. 18, no. 24, pp. 25116-25126, 2010.

[142] S. A. Alexandrov, T. R. Hillman, T. Gutzler, and D. D. Sampson, "Synthetic aperture fourier holographic optical microscopy," Physical Review Letters, vol. 97, no. 16, pp. 168102, 2006.

[143] S. A. Alexandrov, T. R. Hillman, T. Gutzler, and D. D. Sampson, "Synthetic aperture fourier holographic optical microscopy (vol. 97, art. 168102, 2006)," Physical Review Letters, vol. 98, no. 9, pp. 099905, 2007.

[144] S. A. Alexandrov, T. R. Hillman, T. Gutzler, and D. D. Sampson, "Digital Fourier holography enables wide-field, superresolved, microscopic characterization," In the special issue "Optics in 2007 " of Optics \& Photonics News, vol. 18, pp. 29, 2007.

[145] T. R. Hillman, T. Gutzler, S. A. Alexandrov, and D. D. Sampson, "High-resolution, wide-field object reconstruction with synthetic aperture Fourier holographic optical microscopy," Optics Express, vol. 17, no. 10, pp. 7873-7892, 2009.

[146] T. Gutzler, T. R. Hillman, S. A. Alexandrov, and D. D. Sampson, "Coherent aperture-synthesis, wide-field, high-resolution holographic microscopy of biological tissue," Optics Letters, vol. 35, no. 8, pp. 1136-1138, 2010.

[147] S. A. Alexandrov and D. D. Sampson, "Spatial information transmission beyond a system's diffraction limit using optical spectral encoding of spatial frequency," Journal of Optics A: Pure and Applied Optics, vol. 10, no. 2, pp. 025304, 2008. 